\title{
Overexpression of plastidial thioredoxins $f$ and $m$ differentially alters photosynthetic activity and response to oxidative stress in tobacco plants
}

\section{Pascal Rey ${ }^{1,2,3}$ *, Ruth Sanz-Barrio ${ }^{4}$, Gilles Innocenti ${ }^{5}$, Brigitte Ksas ${ }^{1,2,3}$, Agathe Courteille ${ }^{1,2,3}$, Dominique Rumeau ${ }^{1,2,3}$, Emmanuelle Issakidis-Bourguet ${ }^{5}$ and Inmaculada Farran ${ }^{4}$}

\author{
'Laboratoire d'Ecophysiologie Moléculaire des Plantes, Institut de Biologie Environnementale et Biotechnologie, Direction des Sciences du Vivant, \\ Commissariat à l'Energie Atomique, Saint-Paul-lez-Durance, France \\ 2 UMR 7265 Service de Biologie Végétale et de Microbiologie Environnementales, Centre National de la Recherche Scientifique, Saint-Paul-lez-Durance, France \\ ${ }^{3}$ Aix-Marseille Université, Saint-Paul-lez-Durance, France \\ ${ }^{4}$ Instituto de Agrobiotecnología, Universidad Pública de Navarra-Consejo Superior de Investigaciones Científicas, Pamplona, Spain \\ ${ }^{5}$ UMR 8618 Institut de Biologie des Plantes, Centre National de la Recherche Scientifique, Université Paris-Sud, Orsay, France
}

\section{Edited by:}

Jean-Philippe Reichheld, Centre

National de la Recherche Scientifique,

France

\section{Reviewed by:}

Wataru Sakamoto, Okayama

University, Japan

Xia Wu, University of Washington,

USA

\section{${ }^{*}$ Correspondence:}

Pascal Rey, Laboratoire

d'Ecophysiologie Moléculaire des Plantes, Institut de Biologie

Environnementale et Biotechnologie, Direction des Sciences du Vivant,

Commissariat à l'Energie Atomique, Bâtiment 158, SBVME,

CEA-Cadarache, 13108

Saint-Paul-Lez-Durance Cedex, France e-mail:pascal.rey@cea.fr
Plants display a remarkable diversity of thioredoxins (Trxs), reductases controlling the thiol redox status of proteins. The physiological function of many of them remains elusive, particularly for plastidial Trxs $f$ and $m$, which are presumed based on biochemical data to regulate photosynthetic reactions and carbon metabolism. Recent reports revealed that Trxs $f$ and $m$ participate in vivo in the control of starch metabolism and cyclic photosynthetic electron transfer around photosystem I, respectively. To further delineate their in planta function, we compared the photosynthetic characteristics, the level and/or activity of various Trx targets and the responses to oxidative stress in transplastomic tobacco plants overexpressing either $\operatorname{Tr} x$ for $\operatorname{Tr} x \mathrm{~m}$. We found that plants overexpressing $\operatorname{Tr} x \mathrm{~m}$ specifically exhibit altered growth, reduced chlorophyll content, impaired photosynthetic linear electron transfer and decreased pools of glutathione and ascorbate. In both transplastomic lines, activities of two enzymes involved in carbon metabolism, NADP-malate dehydrogenase and NADP-glyceraldehyde-3-phosphate dehydrogenase are markedly and similarly altered. In contrast, plants overexpressing Trx m specifically display increased capacity for methionine sulfoxide reductases, enzymes repairing damaged proteins by regenerating methionine from oxidized methionine. Finally, we also observed that transplastomic plants exhibit distinct responses when exposed to oxidative stress conditions generated by methyl viologen or exposure to high light combined with low temperature, the plants overexpressing $\operatorname{Tr} x$ $\mathrm{m}$ being notably more tolerant than $\mathrm{Wt}$ and those overexpressing $\mathrm{Tr} \mathrm{f}$. Altogether, these data indicate that Trxs $f$ and $m$ fulfill distinct physiological functions. They prompt us to propose that the $m$ type is involved in key processes linking photosynthetic activity, redox homeostasis and antioxidant mechanisms in the chloroplast.

Keywords: antioxidant mechanisms, oxidative stress, photosynthesis, redox homeostasis, thioredoxin, tobacco

\section{INTRODUCTION}

Thioredoxins (Trxs) are ubiquitous and evolutionarily conserved enzymes of $c a .12 \mathrm{kDa}$ catalyzing the reduction of disulfide bonds through a redox-active dithiol CxxC motif (Arnér and Holmgren, 2000). Trxs, discovered 50 years ago in bacteria, cover functions as redox carriers in numerous physiological processes such as DNA synthesis, sulfur assimilation or regulation of transcription factors (Arnér and Holmgren, 2000). In plants, two plastidial Trx types, named $\operatorname{Trx} \mathrm{f}$ and $\operatorname{Trx} \mathrm{m}$, were primarily identified as light-dependent regulators of enzymes related to photosynthetic processes and carbon metabolism (Jacquot et al., 1978; Wolosiuk et al., 1979). Their denomination was based on in vitro ability to activate by reduction fructose-1,6-bisphosphatase (FBPase) and NADP-dependent malate dehydrogenase (NADP-MDH), respectively. These Trxs are reduced by the ferredoxin/thioredoxin system (Wolosiuk and Buchanan, 1977). A third plant Trx type located in cytosol was identified later (Wolosiuk et al., 1979). This type named Trx $\mathrm{h}$ is reduced by cytosolic NADPH thioredoxin reductase (Jacquot et al., 1994) and participates in various processes such as mobilization of seed reserves (Kobrehel et al., 1992) and responses to oxidative stress (Verdoucq et al., 1999).

Whereas most organisms possess a low number (two or three) of Trxs achieving multiple functions, plants display a remarkable diversity of these reductases. A survey of genomic and EST sequences from Arabidopsis and other species revealed the presence of almost 50 genes encoding Trx or Trx-like proteins in higher plants (Meyer etal., 2005). On the basis of gene and peptide sequences, other Trx types, $\mathrm{o}, \mathrm{x}, \mathrm{y}$, and $\mathrm{z}$, have been defined and in Arabidopsis, Trxs f, h, m and y include 2, 9, 4, and 2 isoforms, respectively (Meyer et al., 2005; Lemaire et al., 2007). This outstanding diversity raised the question of functional specialization or redundancy. Genetic studies revealed 
that several plant Trxs possess specific and unique physiological functions in development, metabolism and stress responses. For instance, Arabidopsis mutants deficient in Trx h9 display impaired root and leaf development. This cytosolic Trx is associated with plasma membrane and presumed to participate in cell-to-cell communication processes (Meng et al., 2010). In Arabidopsis plants lacking plastidial $\operatorname{Trx} \mathrm{z}$, chloroplast biogenesis is inhibited revealing a critical role of this Trx (Arsova et al., 2010). $\operatorname{Trx} \mathrm{z}$ has been proposed to regulate transcription via a redox control of plastid-encoded plastid RNA polymerase. In other respects, $\operatorname{Trx} \mathrm{h} 5$ is required for the response to victorin, a fungal toxin inducing programmed cell death in sensitive plants (Sweat and Wolpert, 2007).

Other Trxs participate in plant responses to the oxidative stress conditions resulting from environmental constraints (Vieira Dos Santos and Rey, 2006), mainly due to their ability to provide reducing power to peroxiredoxins (Prxs) and methionine sulfoxide reductases (MSRs), enzymes reducing organic peroxides and repairing oxidized proteins, respectively. Thus, CDSP32 (chloroplastic drought-induced stress protein of $32 \mathrm{kDa}$ ), a double module Trx initially isolated in potato plants subjected to water deficit (Rey et al., 1998) supplies Prxs and MSRs with electrons (Broin etal., 2002; Rey et al., 2005; Tarrago et al., 2010). Another plastidial Trx-like protein, NADPH thioredoxin reductase C (NTRC), uses NADPH to reduce 2-Cys Prx and has been proposed as a protection system against oxidative damage (Pérez-Ruiz et al., 2006). Trxs $\mathrm{x}$ and y are also presumed to participate in responses to oxidative stress based on their ability to reduce Prxs and MSRs in vitro (Collin et al., 2003, 2004; Navrot et al., 2006; Vieira Dos Santos et al., 2007), but evidence for such a function in planta is still scarce. Very recently, we showed that Trx y 2 maintains growth under high light and long day in Arabidopsis, likely through electron supply to plastidial MSRs (Laugier et al., 2013). Note that the other Trx y isoform, $\mathrm{y} 1$, which is specifically expressed in non-photosynthetic organs (Collin et al., 2004) could also fulfill a protective function in seeds, in which MSRs likely play a key role in preserving longevity (Châtelain et al., 2013).

Although Trxs $\mathrm{f}$ and $\mathrm{m}$ have been the first Trxs discovered in plants, the knowledge concerning their physiological functions is only emerging. Based on biochemical studies, Trxs $f$ and $\mathrm{m}$ are presumed to regulate photosynthesis and carbon metabolism although Trx $\mathrm{f}$ seems more efficient than $\operatorname{Trx} \mathrm{m}$ to redox regulate most enzymes involved in these processes. $\operatorname{Trx} \mathrm{f}$ specifically activates glyceraldehyde-3-phosphate dehydrogenase (B-containing GAPDH isoforms) and FBPase, and controls the activity of other redox-sensitive enzymes like NADP-MDH and glucose-6-phosphate dehydrogenase (G6PDH; Collin et al., 2003; Lemaire et al., 2007; Marri et al., 2009; Née et al., 2009). Similarly, Trx m reduces enzymes involved in carbon metabolism and catabolism such as NADP-MDH and G6PDH, but also regenerates the activity of enzymes involved in antioxidant mechanisms like Prxs and MSRs (Collin et al., 2003; Vieira Dos Santos et al., 2007). Among Trx $m$ isoforms, Trx m3 displays highly distinct properties, since it cannot reduce known Trx targets (Collin et al., 2003; Vieira Dos Santos et al., 2007). This isoform, expressed in non-green plastids of meristems and organ primordia, could be involved in redox regulation of symplastic permeability (BenitezAlfonso et al., 2009). Using RNA-interference, Chi et al. (2008) showed that rice plants knockdown for Trx m expression display abnormal chloroplast development and impaired growth. In contrast, no obvious phenotype was observed in Arabidopsis plants lacking either Trx m1 or Trx m4 (Laugier et al., 2013). But, most interestingly, Trx m4-deficient mutant plants specifically display strongly increased cyclic photosynthetic electron transfer around PSI (Courteille et al., 2013). Only very recent papers brought information regarding the physiological function of Trx $f$. In pea plants displaying a dramatically reduced $\operatorname{Trx} f$ transcript level due to silencing, no phenotype was noticed (Luo et al., 2012). Similarly, no change was found in growth and photosynthesis in Arabidopsis knockout lines for Trx f1, but reduced light-activation of ADP-glucose pyrophosphorylase (AGPase) in leaves accompanied by a decrease in starch accumulation was observed in these mutants (Thormählen et al., 2013). Consistently, we observed that transplastomic tobacco plants overexpressing Trx $\mathrm{f}$ show a strong increase in starch content (Sanz-Barrio et al., 2013).

The data gained in various species indicate that $\operatorname{Tr} \mathrm{f}$ is involved in the regulation of starch metabolism, whereas the role of $\operatorname{Trx} \mathrm{m}$ seems more complex. In this work, we compare the phenotypes of tobacco plants overexpressing either $\operatorname{Trx} \mathrm{f}$ or $\operatorname{Trx} \mathrm{m}$ with regards to growth, photosynthetic metabolism, activation and content of Trx targets and response to oxidative stress. We show that overexpression of Trx m leads to delayed growth, reduced pigment content and impaired photosynthetic activity. Further, we found a differential behavior of plants overexpressing $\operatorname{Trx} f$ or $\operatorname{Tr} x \mathrm{~m}$ exposed to oxidative stress conditions, revealing that $\operatorname{Tr} \mathrm{m}$ very likely displays, compared to $\operatorname{Trx} \mathrm{f}$, a broader range of physiological functions.

\section{MATERIALS AND METHODS PLANT MATERIAL AND STRESS TREATMENTS}

Nicotiana tabacum L. plants, cv Petit Havana (Wt and transplastomic lines), were sown and grown on compost in phytotron under a 12 -h photoperiod $\left(300 \mu \mathrm{mol}\right.$ photons $\left.\mathrm{m}^{-2} \mathrm{~s}^{-1}\right)$ and a $25^{\circ} \mathrm{C} / 19^{\circ} \mathrm{C}$ (day/night) temperature regime for standard conditions. Transplastomic plants overexpressing either Trx f or Trx $m$ were generated and characterized as reported in Sanz-Barrio et al. (2013). Photosynthetic and biochemical analyses were carried out on young well-expanded leaves from 35- to 40-day old plants.

Photooxidative treatment was carried out by exposing 30-dayold tobacco plants grown under standard conditions to high light intensity $\left(950 \mu \mathrm{mol}\right.$ photons $\left.\mathrm{m}^{-2} \mathrm{~s}^{-1}\right)$ and low temperature $\left(8^{\circ} \mathrm{C}\right)$ for 5 to 8 days under a 12-h photoperiod. Methyl viologen (MV) treatment was performed both on whole plants and leaf disks. For whole plant experiments, 40-day-old tobacco plants were sprayed with $30 \mu \mathrm{M}$ MV in $0.05 \%(\mathrm{v} / \mathrm{v})$ Tween 20 and placed in phytotron under $200 \mu \mathrm{mol}$ photons $\mathrm{m}^{-2} \mathrm{~s}^{-1}$ and a 16 -h light $\left(28^{\circ} \mathrm{C}\right) / 8-\mathrm{h}$ dark $\left(25^{\circ} \mathrm{C}\right)$ photoperiod. Leaf damage caused by MV was photographed 2 days after treatment. For leaf disk experiments, 15 disks (12 mm diameter) were punched from young fully expanded leaves from 40-day-old plants, floated topside up on $15 \mathrm{~mL}$ of water or $1 \mu \mathrm{M} \mathrm{MV}$, and illuminated at $600 \mu \mathrm{mol}$ photons $\mathrm{m}^{-2} \mathrm{~s}^{-1}$ and $28^{\circ} \mathrm{C}$ during $14 \mathrm{~h}$. Electrolyte content in solution was measured 
after treatment using a HI9813-5 conductivity meter (Hanna Instruments, Woonsocket, RI, USA). Total electrolyte content was determined in the same way after autoclaving samples. Results were expressed as the percentage of total electrolytes released after treatment.

\section{PHOTOSYNTHETIC MEASUREMENTS}

Chlorophyll fluorescence parameters were measured using a PAM2000 modulated fluorometer (Waltz Effeltrich, Germany) as previously described (Havaux et al., 2000). A saturating pulse of white light was applied on leaf and measurements were recorded during actinic light illumination (from 25 to $2,500 \mu \mathrm{mol}$ photons $\mathrm{m}^{-2} \mathrm{~s}^{-1}$ ). The PSII photochemical efficiency ( $\left.\Phi_{\mathrm{PSII}}\right)$ during actinic illumination was estimated by calculating $\Delta F / F_{\mathrm{m}^{\prime}}$, where $\Delta F$ is the steady-state chlorophyll fluorescence level and $F_{\mathrm{m}^{\prime}}$ is the maximal level. NPQ (non-photochemical quenching) reflects the dissipation of absorbed light energy from PSII as heat. NPQ was calculated as $\left(F_{\mathrm{m}} / F_{\mathrm{m}^{\prime}}\right)-1$ where $F_{\mathrm{m}}$ is the maximal fluorescence level in the dark.

\section{ANALYSIS OF CHLOROPHYLL CONTENT}

One-cm diameter leaf disks were collected from fully expanded mature leaves and immediately frozen in liquid nitrogen and stored at $-80^{\circ} \mathrm{C}$ until use. Leaf disks were crushed in $1 \mathrm{~mL} 80 \%$ acetone. After storing overnight in the dark at $4^{\circ} \mathrm{C}$ and centrifugation $(14,000 \mathrm{~g}, 10 \mathrm{~min})$, the content in chlorophylls $a$ and $b$ was measured spectrophotometrically and calculated according to Lichtenthaler (1987).

\section{GLUTATHIONE CONTENT}

Three tobacco leaf disks of $1 \mathrm{~cm}$ diameter (about $100 \mathrm{mg}$ ) were ground to a fine powder in liquid nitrogen and extracted in $1 \mathrm{~mL}$ $6.3 \mathrm{mM}$ diethylene triamine-pentaacetic acid (DTPA), $40 \mu \mathrm{M}$ $N$-acetyl-L-cysteine and $0.15 \%$ trifluoroacetic acid (TFA). After centrifugation $(15,000 \mathrm{~g}, 10 \mathrm{~min})$, the supernatant containing non-protein thiols was filtered on $0.2 \mathrm{~mm}$ nylon membrane. $125 \mu \mathrm{l}$ were added to $225 \mu \mathrm{L}$ buffer A (6.3 mM DTPA, $0.2 \mathrm{M}$ 4-(2-hydroxyethyl)-piperazine-1-propane-sulfonic acid, $\mathrm{pH} 8.2$ ) or buffer B (buffer A +0.5 mM Tris(2-carboxy-ethyl)phosphine hydrochloride, TCEP). For measurements of GSH content, samples in buffer A were immediately alkylated with monobromobimane in acetonitrile at a final concentration of $500 \mu \mathrm{M}$ and stabilized by adding $150 \mu \mathrm{L}$ cold $1 \mathrm{M}$ methane sulfonic acid following $20 \mathrm{~min}$ incubation in the dark. For measurements of total glutathione (GSH), samples in buffer B were alkylated for $45 \mathrm{~min}$ at room temperature. Reactions were stopped by adding $150 \mu \mathrm{L}$ of cold $1 \mathrm{M}$ methane sulfonic acid. $20 \mu \mathrm{l}$ were analyzed by HPLC and measurements of the fluorescence of bimane derivates were carried out as in Collin et al. (2008). Quantification of GSH amount was based on peak area and calibration was performed using GSH (Sigma). The concentration of oxidized glutathione (GSSG) was calculated as the difference between total GSH and reduced GSH values.

\section{ASCORBIC ACID CONTENT}

Ascorbate (AsA) was analyzed by HPLC as described by Havaux et al. (2005). Three leaf disks of $1 \mathrm{~cm}$ in diameter were ground in $750 \mu \mathrm{L} 0.1 \mathrm{M}$ metaphosphoric acid. Samples were filtered on nylon $0.2 \mu \mathrm{M}$ membrane (Spin-X Costar). $6 \mu \mathrm{L}$ were immediately injected for assaying reduced ascorbate. Total ascorbate was measured in the same volume following reduction of dehydroascorbic acid into ascorbic acid using $10 \mathrm{mM}$ TCEP for $2 \mathrm{~h}$ in the dark at $25^{\circ} \mathrm{C}$. AsA was detected at $245 \mathrm{~nm}$ in sulfuric acidacidified water $(\mathrm{pH} 2.5)$ at a retention time of 1 min under a $0.65 \mathrm{~mL} \mathrm{m^{-1 }}$ flow. Quantification of AsA amount was based on peak area and calibration was performed using AsA from Sigma.

\section{PROTEIN EXTRACTION, SDS-PAGE AND WESTERN ANALYSIS}

Leaf pieces were blended in liquid nitrogen, and the powder was used to prepare soluble proteins as described in Rey et al. (2005). The protein content was determined using the BC Assay Reagent (Interchim, Montluçon, France). Proteins were separated using SDS-PAGE and Coomassie Brilliant Blue staining of gels was carried out to check quality of protein extracts. For immunoblot analysis following electrophoresis, proteins were electro-transferred onto nitrocellulose membrane (Pall Corporation, Ann Arbor, MI, USA) and Red Ponceau staining was achieved to ensure equal loading in all lanes. Western analysis was carried out using primary antibodies raised in rabbit against NtTrx $\mathrm{m}$ or NtTrx f (1:5,000; Sanz-Barrio et al., 2011), AtMSRB1 and AtMSRB2 (1:1,000; Laugier et al., 2010), poplar PrxQ (1:2,000; Rouhier et al., 2004) and catalase (1:1,000; Agrisera, Vännas, Sweden). Western analysis of 2-Cys Prx abundance and redox status was performed as in Rey et al. (2007). Bound antibodies were detected using either an anti-rabbit IgG alkaline phosphatase conjugate (Sigma-Aldrich) or a goat anti-rabbit “Alexa Fluor ${ }^{\circledR} 680$ ” IgG from Invitrogen diluted 1:10,000. When using the latter, antibodies were revealed at $680 \mathrm{~nm}$ using the "Odyssey Infrared Imager" from Licor.

\section{NADP-MDH AND NADP-GAPDH ACTIVITY ASSAYS}

NADP-dependent malate and glyceraldehyde-3-phosphate dehydrogenases activities in tobacco leaf crude extracts were assayed spectrophotometrically as previously described in Keryer et al. (2004) and Marri et al. (2009), respectively. Extractable enzymatic activities were measured on aliquots of freshly prepared extracts and maximal activities were measured after pre-treatment (reductive activation) of extracts with $25 \mathrm{mM}$ DTT for $20 \mathrm{~min}$ at room temperature.

\section{MSR ACTIVITY ASSAY}

Maximal MSR activity in tobacco leaf extracts was assayed by monitoring the reduction of the synthetic substrate, dabsyl-MetO, in the presence of DTE (Vieira Dos Santos et al., 2005; Laugier et al., 2010). After blending leaves and suspension in extraction buffer, the content in soluble proteins was determined as above. The reaction mixture contained $15 \mathrm{mM}$ HEPES $\mathrm{pH} 8,10 \mathrm{mM}$ $\mathrm{MgCl}_{2}$, $30 \mathrm{mM} \mathrm{KCl}, 20 \mathrm{mM}$ DTE, $0.25 \mathrm{mM}$ dabsyl-MetO and 30 or $300 \mu \mathrm{g}$ soluble proteins. After incubation for $3 \mathrm{~h}$ at $37^{\circ} \mathrm{C}$, stopping using an ethanol:acetate buffer (50:50) and centrifugation, a supernatant aliquot was loaded on a C18 reverse phase $3.5 \mu \mathrm{m}$, $3 \mathrm{~mm} \times 50 \mathrm{~mm}$ column SunFire ${ }^{\mathrm{TM}}$ (Waters, Milford, MA, USA) to separate dabsyl-MetO and dabsyl-Met. 


\section{RESULTS}

GROWTH CHARACTERISTICS OF TOBACCO PLANTS OVEREXPRESSING Trx f OR Trx m

The transplastomic tobacco plants studied in this work were generated as described previously (Sanz-Barrio et al., 2013) by inserting tobacco Trx f or Trx m sequences (GenBank Acc. N HQ338526 and HQ338525, respectively) without predicted transit peptides in the chloroplast genome under the control of the $p s b A$ regulatory sequence. Compared to $\mathrm{Wt}$, the tobacco transformant lines termed $\operatorname{Trx} \mathrm{f}^{+}$and $\operatorname{Tr} \mathrm{m}^{+}$were shown to contain strongly increased $\operatorname{Trx}$ protein levels (at least 20 times more for $\operatorname{Trx} \mathrm{f}^{+}$and 15 times for $\operatorname{Tr} x$ $\mathrm{m}^{+}$; Sanz-Barrio et al., 2013 and data not shown). The first phenotype analysis revealed that compared to Wt and $\operatorname{Trx} \mathrm{f}^{+}$plants, Trx $\mathrm{m}^{+}$plants display some delay (2-3 days) in germination in in vitro conditions, a pale-green phenotype and a delay of few days in flowering time when grown in greenhouse conditions (SanzBarrio et al., 2013). In the present work, we further investigated the growth parameters of the transplastomic lines grown on compost in phytotron conditions. We noticed that plants overexpressing $\operatorname{Tr} x$ $m$ do not exhibit any delay in germination in these conditions, but show a slower growth compared to Wt and those overexpressing Trx $\mathrm{f}$ (Figures 1A-C). Thus at 40 days, the height stem of $\operatorname{Trx} \mathrm{m}^{+}$ plants $(15.3 \pm 2.1 \mathrm{~cm})$ is significantly lower than that of Wt plants $(22.9 \pm 6.5 \mathrm{~cm})$, whereas the growth of $\operatorname{Trx} \mathrm{f}^{+}$plants is slightly altered, their height stem being $19.3 \pm 5 \mathrm{~cm}$ (Figure 1C). The slower growth of $\operatorname{Trx~} \mathrm{m}^{+}$plants is associated with some delay ( $c a$. 3 days) in flowering, but the plant size at this developmental stage is very similar to that of $\mathrm{Wt}$ and $\operatorname{Trx} \mathrm{f}^{+}$plants (data not shown), as previously observed (Sanz-Barrio et al., 2013). We determined the leaf specific weight and did not notice any difference for the three lines (Table 1). Regarding the dry matter percentage, we observed a slightly, but significantly higher ratio in $\operatorname{Trx} \mathrm{f}^{+}$plants (Table 1).
Table 1 | Leaf specific weight, dry matter percentage and chlorophyll content in 40-day old Wt and transplastomic tobacco plants.

\begin{tabular}{llll}
\hline Genotype & Wt & Trx f & Trx $\mathbf{~}^{+}$ \\
\hline Leaf specific weight & $21.4 \pm 0.9$ & $20.8 \pm 1.6$ & $21.0 \pm 1.7$ \\
(mg FW cm & $-2)$ & & \\
$\%$ Dry matter & $10.3 \pm 0.8$ & $11.4 \pm 1.1^{*}$ & $10.2 \pm 1.3$ \\
Chl $\left(\mu \mathrm{g} \mathrm{cm}^{-2}\right)$ & $44.6 \pm 1.4$ & $41.1 \pm 1.0^{* *}$ & $30.9 \pm 1.3^{* * *}$ \\
Chl $a\left(\mu \mathrm{g} \mathrm{cm}^{-2}\right)$ & $31.6 \pm 1.7$ & $28.9 \pm 1.0^{*}$ & $23.4 \pm 1.0^{* * *}$ \\
Chl $b\left(\mu \mathrm{g} \mathrm{cm}^{-2}\right)$ & $13.0 \pm 0.6$ & $12.2 \pm 1.1$ & $7.6 \pm 0.3^{* * *}$ \\
$\mathrm{Chl} a / \mathrm{Chl} b$ & $2.4 \pm 0.2$ & $2.4 \pm 0.2$ & $3.1 \pm 0.1^{* * *}$
\end{tabular}

Chlorophyll content was measured in young well-expanded leaves of 40-day old $W t$ and transplastomic tobacco plants. Chlorophyll data are mean values $\pm S D$ from five independent measurements per plant and genotype. Leaf specific weight and dry matter data are mean values $\pm S D$ from eight independent measurements per plant and genotype. Each measurement was carried out using three 1-cm leaf disks. Wt, wild-type; $\operatorname{Tr} x \mathrm{f}^{+}$and $\operatorname{Tr} x \mathrm{~m}^{+}$, plants overexpressing $\operatorname{Trx} f$ or Trx $m$, respectively. Values significantly different from Wt values with ${ }^{*} p<0.05,{ }^{*} p<0.01$, and ${ }^{* * *} p<0.001$ (t-test).

This characteristic could originate from the much higher starch content measured in this line (Sanz-Barrio et al., 2013).

We then measured chlorophyll content in fully expanded leaves (Table 1) and observed that $\operatorname{Tr} \mathrm{f}^{+}$plants display a pigment content slightly, but significantly, lower than that of Wt ( $41.1 \pm 1.0$ against $44.6 \pm 1.4 \mu \mathrm{g} \mathrm{cm}^{-2}$ ). This difference has not been observed when plants were grown in greenhouse under longer photoperiod and higher temperature (Sanz-Barrio et al., 2013). Thus, we presume that this phenotype feature originates from the different environmental conditions used in the present study. Consistent with visual observations, a chlorophyll content reduced by more than $30 \%$
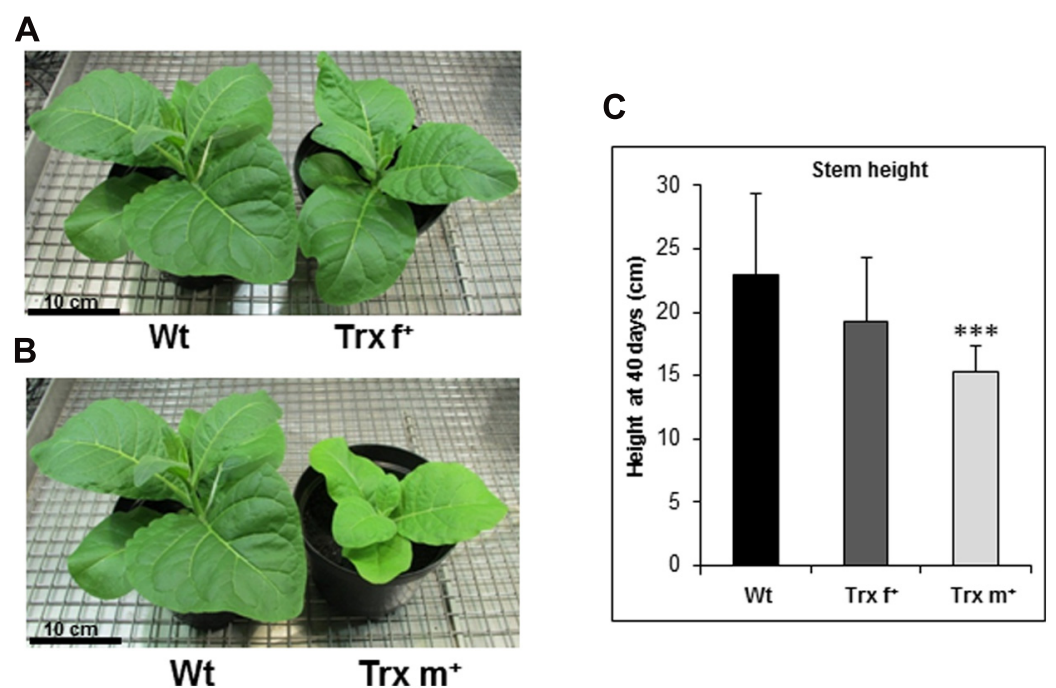

FIGURE 1 | Growth of transplastomic tobacco plants overexpressing Trx f or Trx m. (A) Wt and $\operatorname{Trx} \mathrm{f}^{+}$plants grown in phytotron for 35 days in standard conditions $\left(300 \mu \mathrm{mol}\right.$ photons $\mathrm{m}^{-2} \mathrm{~s}^{-1}, 12-\mathrm{h}$ photoperiod and $25^{\circ} \mathrm{C} / 19^{\circ} \mathrm{C}$, day/night). (B) $\mathrm{Wt}$ and $\mathrm{Trx} \mathrm{m}^{+}$plants grown in phytotron for 35 days under standard conditions. The same Wt plant is shown in panels (A) and (B). (C) Stem height of Wt and transplastomic plants grown for 40 days in standard conditions. Mean stem height values $\pm S D$ were gained from 15 plants per genotype. Wt, wild-type; $\operatorname{Tr} x \mathrm{f}^{+}$and $\operatorname{Tr} x \mathrm{~m}^{+}$, plants overexpressing $\operatorname{Tr} \mathrm{f}$ or $\operatorname{Tr} \mathrm{m}$, respectively. ${ }^{* *}$ Significantly different from $W t$ with $p<0.001$ ( $t$-test). 
$\left(30.9 \pm 1.3 \mu \mathrm{g} \mathrm{cm}^{-2}\right)$ compared to Wt was recorded in $\operatorname{Tr} \mathrm{m} \mathrm{m}^{+}$ plants. Note that when plants were grown at higher temperature, the pigment content was reduced in a less pronounced manner (-25\%; Sanz-Barrio et al., 2013). The chlorophyll $a$ /chlorophyll $b$ ratio was similar (2.4) in both $\mathrm{Wt}$ and $\operatorname{Trx} \mathrm{f}^{+}$plants, but higher (3.1) in $\operatorname{Trx} \mathrm{m}^{+}$plants (Table 1), due to a chlorophyll $b$ content reduced to a larger extent $(-42 \%$ compared to $\mathrm{Wt})$ than that of chlorophyll $a$ (-26\%; Table 1).

\section{PHOTOSYNTHETIC PROPERTIES OF TOBACCO PLANTS OVEREXPRESSING Trx f OR Trx m}

We then investigated the photosynthetic properties of transplastomic tobacco plants and first measured maximal PSII photochemical efficiency (Figure 2A) by recording the chlorophyll fluorescence parameter, $F_{\mathrm{V}} / F_{\mathrm{m}}$, which reflects the PSII capacity to reduce the primary $Q_{A}$ electron acceptor. We observed a typical value close to 0.8 in Wt plants $(0.793 \pm 0.007)$. A slightly altered $F_{\mathrm{v}} / F_{\mathrm{m}}$ value $(0.766 \pm 0.017)$ was recorded in the $\operatorname{Trx} \mathrm{f}^{+}$line, whereas this fluorescence parameter was noticeably reduced in plants overexpressing $\operatorname{Trx} \mathrm{m}(0.692 \pm 0.028)$. These data reveal impairment in PSII functioning in plants accumulating Trx m. Photosynthetic electron transport activity was also estimated by measuring $\Phi_{\text {PSII }}$, a chlorophyll fluorescence parameter indicative of the efficiency of PSII photochemistry as a function of light intensity. While only slightly decreased in $\operatorname{Trx} \mathrm{f}^{+}$ plants, PSII photochemical performance appeared more impaired in plants overexpressing Trx $\mathrm{m}$ (Figure 2B). Thermal dissipation of absorbed light energy, expressed by the NPQ of chlorophyll fluorescence coefficient, was also recorded in the different lines (Figure 2C). No noticeable difference was detected between $\mathrm{Wt}$ and $\operatorname{Trx}^{+}$transplastomic lines since they displayed a similar ability to recover photosynthesis and PSII photochemical efficiency following light irradiation.

\section{ACTIVITY OF TrX TARGETS INVOLVED IN CARBON METABOLISM}

To get evidence that overexpression of plastidial Trxs has a functional impact in planta on Trx target proteins, we first measured in leaves of transplastomic lines the activities of two well-known Trx-regulated enzymes, NADP-dependent $\mathrm{MDH}$ and GAPDH (Lemaire et al., 2007). Both Trx $\mathrm{f}^{+}$and $\operatorname{Trx} \mathrm{m}^{+}$plants show similar marked changes in enzymatic activities. Extractable leaf activities were very strongly lowered to $c a .40$ and $30 \%$ of the Wt value for $\mathrm{MDH}$ and GAPDH, respectively (Figures 3A,B, left panels). Conversely, leaf $\mathrm{MDH}$ and GAPDH capacities corresponding to the maximal activities measured in extracts chemically reduced with DTT, which allows Trx reduction but not direct Trx-target activation, were substantially increased in both transplastomic lines (Figures 3A,B, right panels). These findings show that overexpressed Trxs modulate the activity of known targets in planta. Further, they indicate that both Trx $\mathrm{f}$ and $\mathrm{m}$, when they are in large excess, regulate NADP-dependent $\mathrm{MDH}$ and GAPDH enzymes in a similar manner.

\section{Prx AND MSR ABUNDANCE}

Peroxiredoxins are ubiquitous thiol-based peroxidases detoxifying hydrogen and organic peroxides. In plants, several Trx types such as NTRC, Trx x, CDSP32 and Trx y supply with electrons the main Prx plastidial type, 2-Cys Prx, and another isoform, PrxQ (Dietz, 2011). We thus investigated the abundance of these Prxs in tobacco plants by performing Western analysis. First, we confirmed the high abundance of Trxs $\mathrm{f}$ and $\mathrm{m}$ in transplastomic lines (Figure 4A). The antibodies raised against Arabidopsis 2-Cys Prx
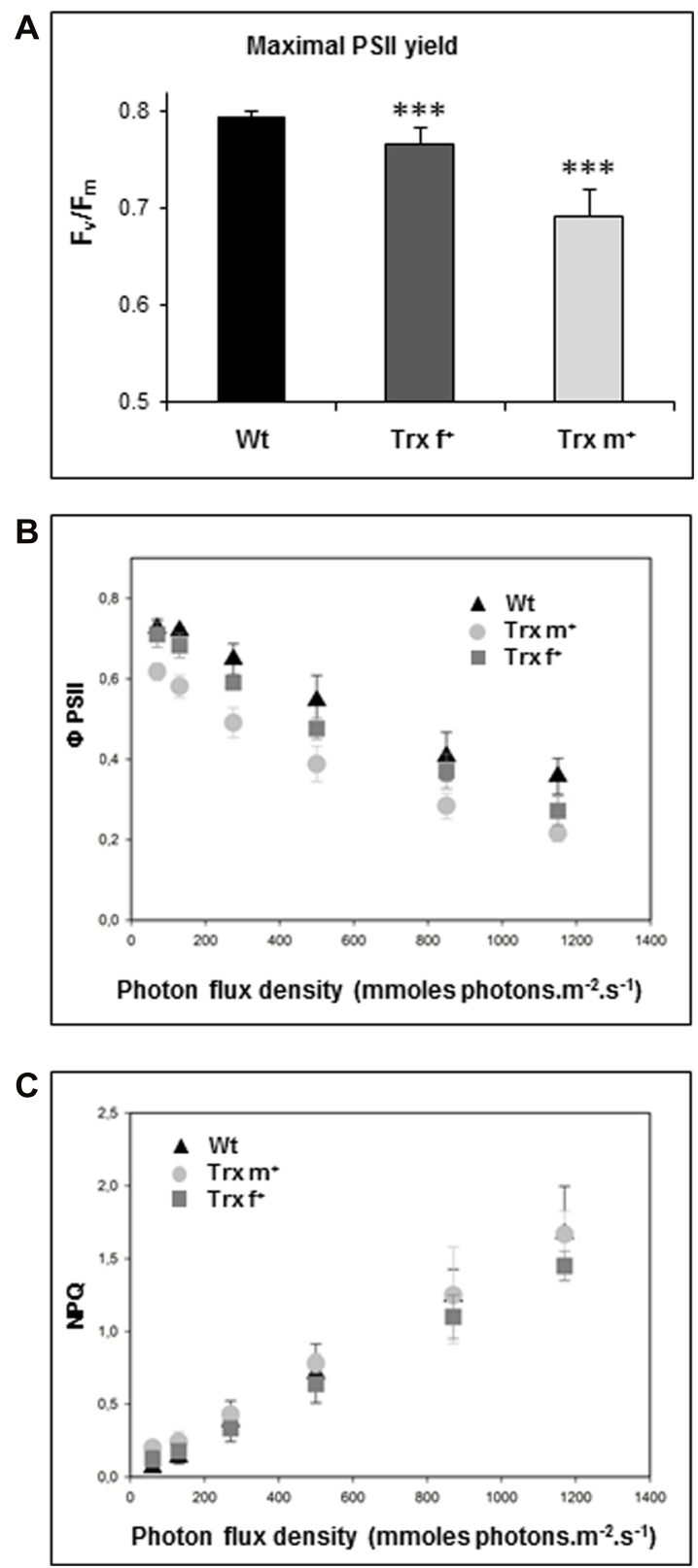

FIGURE 2 | Photosynthetic fluorescence parameters of transplastomic tobacco plants overexpressing Trx f orTrx m. (A) Maximal photosystem II photochemical efficiency in tobacco plants $\left(F_{\mathrm{v}} / F_{\mathrm{m}}\right)$. (B) Effective photosystem II yield (ФPSII). (C) Non-photochemical quenching (NPQ). Light response curves are shown for $\Phi P S I I$ (B) and NPQ (C). Measurements were achieved in leaves from 35-day-old Wt and transplastomic tobacco plants grown in standard conditions. Data are mean values $\pm S D$ from at least five independent measurements per genotype. Wt, wild-type; $\operatorname{Tr} x \mathrm{f}^{+}$and $\operatorname{Tr} \mathrm{x} \mathrm{m}^{+}$, plants overexpressing $\operatorname{Tr} \mathrm{f}$ or $\operatorname{Tr} \mathrm{x} \mathrm{m}$, respectively. ${ }^{* *}$ Significantly different from $W t$ with $p<0.001$ ( $t$-test). 


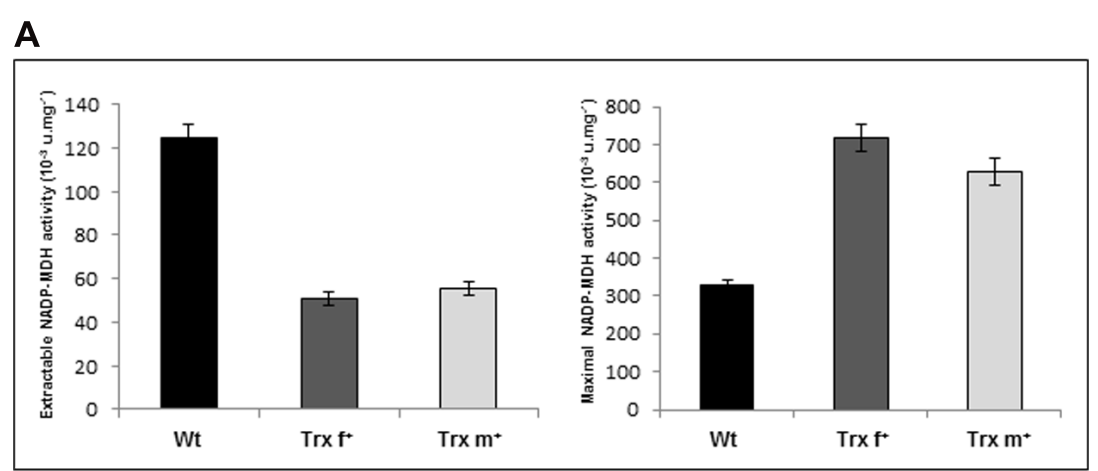

B

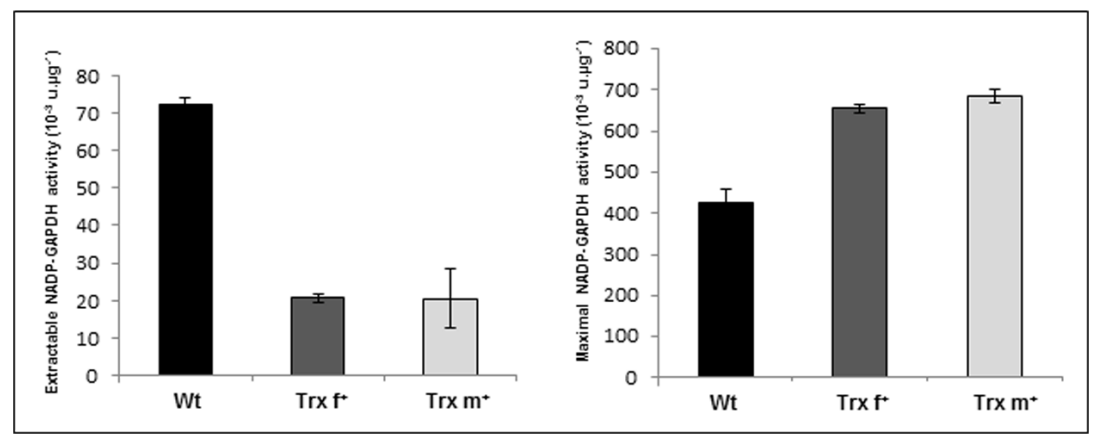

FIGURE 3 | NADP-dependent malate and glyceraldehyde-3-phosphate dehydrogenases enzymatic activities in leaf extracts from transplastomic tobacco plants overexpressing Trx $f$ or Trx $m$. (A) Extractable and maximal NADP-MDH activities. (B) Extractable and maximal NADP-GAPDH activities. Maximal activities (capacities) were measured after a reducing treatment of protein leaf extracts $25 \mathrm{mM}$ $\mathrm{DTT}, 20 \mathrm{~min}$ at room temperature). Data are mean values $\pm \mathrm{SD}$ from at least four independent measurements per genotype. Wt, wild-type; $\operatorname{Tr} x \mathrm{f}^{+}$and $\operatorname{Tr} x \mathrm{~m}^{+}$, plants overexpressing $\operatorname{Tr} \mathrm{f}$ or $\operatorname{Trx} \mathrm{m}$, respectively. and poplar PrxQ homologues specifically revealed bands with the expected molecular masses in tobacco extracts (Figure 4B). No change was detected in the amount of the two plastidial Prxs in $\operatorname{Trx}^{+}$plants (Figure 4B). We also used antibodies raised against overoxidized 2-Cys Prx, an inactivated form possibly involved in signaling processes related to redox homeostasis (Rey et al., 2007). Whereas there was no change in 2-Cys Prx abundance in plants overexpressing Trx f or Trx $\mathrm{m}$ compared to $\mathrm{Wt}$, we observed a more variable amount of overoxidized 2-Cys Prx in the same leaf extracts. We noticed that such a variation occurred within the same genetic background (Figure 4B). A quantitative analysis, performed on data gained from six independent plants per line (data not shown), lead us to conclude that there was no significant variation in the 2-Cys Prx redox status in transplastomic tobacco plants.

Methionine sulfoxide reductase enzymes, which repair oxidized methionine in proteins, are also well-known targets of Trxs involved in plant responses to environmental constraints (Laugier et al., 2010). The abundance of plastidial MSRs was investigated in tobacco plants using sera raised against Arabidopsis MSRB1, MSRB2 and poplar MSRA4. MSRA4 antiserum recognized two bands at ca. $25 \mathrm{kDa}$ in tobacco extracts (Figure 4C), corresponding to the reduced and oxidized forms of plastidial MSRA as observed in other species (Vieira Dos Santos et al., 2005; Bouchenak et al., 2012; Marok etal., 2013). No substantial change was observed regarding the abundance of MSRA4 forms in Trx-overexpressing plants compared to Wt. For MSRB1, no unambiguous signal could be detected in tobacco extracts due to poor cross reactivity of the serum generated against Arabidopsis homologue (data not shown). Like in Arabidopsis extracts, a faint band at ca. $15 \mathrm{kDa}$ was revealed for MSRB2, next to a lower non-specific and intense band (Laugier et al., 2010). Again, overexpression of either Trx f or Trx m was not found to result in any substantial change in the amount of this plastidial MSR isoform. Altogether, Western data reveal that the levels of some major Trx targets involved in antioxidant mechanisms are not modified when Trxs $\mathrm{f}$ and $\mathrm{m}$ are overproduced.

\section{LEAF MSR CAPACITY}

We then measured the MSR enzymatic capacity in leaf extracts from tobacco plants using dabsyl-MetO, a substrate mimicking peptide-bound MetO (Figure 4D). In Wt, a maximal activity in the range of $22 \mathrm{pmol}$ Met. $\mathrm{mg}_{\text {prot }}{ }^{-1} \mathrm{~min}^{-1}$ was measured in the presence of reductant. Note that this value is noticeably lower than that measured in Arabidopsis, ca. 50 pmol Met. $\mathrm{mg} \mathrm{prot}^{-1} \mathrm{~min}^{-1}$ (Laugier et al., 2010), but higher than that recorded in barley, ca. 10 pmol Met. mg $\operatorname{prot}^{-1} \min ^{-1}$ (Marok et al., 2013). In Trx $\mathrm{f}^{+}$plants, a rather similar value was found, ca. $25 \mathrm{pmol}$ Met. mg prot ${ }^{-1} \mathrm{~min}^{-1}$. In sharp contrast, a twice higher value (46 pmol Met. mg prot ${ }^{-1} \mathrm{~min}^{-1}$ ) was measured in plants overexpressing $\operatorname{Tr} x \mathrm{~m}$. These data, showing a more elevated MSR capacity 
A

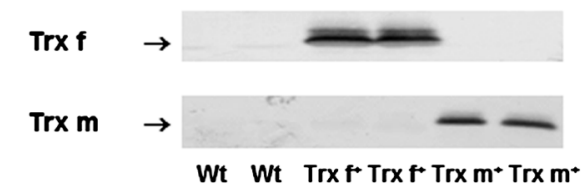

C

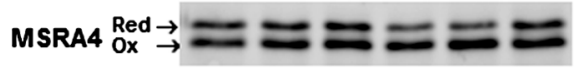

MSRB2

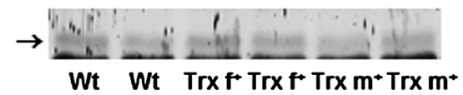

E

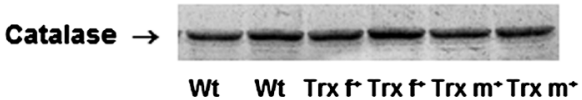

FIGURE 4 | Abundance of proteins involved in antioxidant mechanisms and leaf peptide methionine sulfoxide reductase enzymatic capacity in leaf extracts from transplastomic tobacco plants overexpressing Trx $f$ or Trx $\mathbf{m}$. (A) Western analysis of $\operatorname{Tr} x \mathrm{f}$ and $\operatorname{Tr} x \mathrm{~m}$ abundance. (B) Western analysis of the abundance and redox status of plastidial 2-Cys peroxiredoxin (2-Cys Prx) and of the abundance of peroxiredoxin Q (PrxQ). (C) Western analysis of the abundance of plastidial methionine sulfoxide reductases A4 and B2, MSRA4 and MSRB2, respectively. (D) Peptide methionine sulfoxide
B

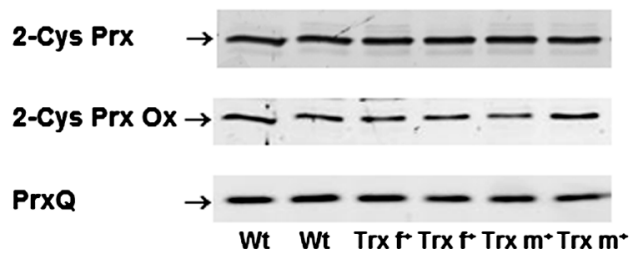

D

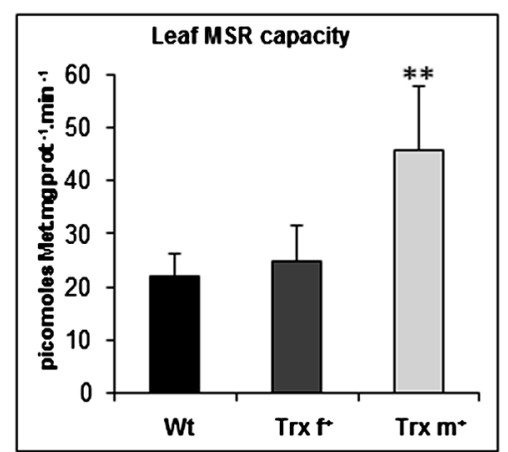

reductase enzymatic capacity measured using HPLC in crude leaf extracts using dabsyl-MetO, a synthetic substrate mimicking peptide-bound MetO. Data are mean values \pm SD from at least five independent measurements per genotype. ${ }^{*}$ Significantly different from Wt with $p<0.01$ ( $t$-test). (E) Western analysis of catalase abundance. Similar Western data were obtained using leaf extracts from two independent plants originating from at least two distinct growth experiments. Wt, wild-type; $\operatorname{Tr} x \mathrm{f}^{+}$and $\operatorname{Tr} \times \mathrm{m}^{+}$, plants overexpressing $\operatorname{Trx}$ f or $\operatorname{Trx} m$, respectively. in $\operatorname{Trx} \mathrm{m}^{+}$plant extracts, reveal that in planta Trx $\mathrm{m}$, but not $\operatorname{Trx} \mathrm{f}$, very likely regenerates and sustains the activity of plastidial MSRs.

\section{CATALASE ABUNDANCE}

The previous data revealed that Trx m likely provides reducing power to MSRs. MSRs are enzymes repairing oxidized proteins, but could also play a more general antioxidant function since their action results in ROS scavenging at the expense of NADPH (Moskovitz et al., 1997). To further analyze a putative function of plastidial Trxs in the control of redox homeostasis in plant cells, we analyzed leaf catalase abundance using Western blot analysis. Catalase is one major enzymatic system responsible for $\mathrm{H}_{2} \mathrm{O}_{2}$ scavenging in plant cells. We did not notice any substantial difference in catalase amount in plants overexpressing either $\operatorname{Tr} \mathrm{f}$ or Trx m compared to Wt (Figure 4E), likely indicating no important change in the catalase-based capacity for detoxifying $\mathrm{H}_{2} \mathrm{O}_{2}$ in these lines.

\section{CONTENT AND REDOX STATUS OF GLUTATHIONE AND ASCORBATE}

We then investigated whether non-enzymatic antioxidant systems could be altered in transplastomic tobacco lines and measured the leaf content in GSH and ascorbate, which are abundant soluble antioxidants fulfilling key roles in redox homeostasis (Noctor and Foyer, 1998). In young well-expanded leaves of 40-day-old $\mathrm{Wt}$ tobacco plants, a GSH content of $c a .0 .90 \mu \mathrm{mol} \mathrm{g} \mathrm{FW}{ }^{-1}$ was measured, the proportion of reduced form being 91\% (Figures 5A,B).
In $\operatorname{Tr} x \mathrm{f}^{+}$plants, the content and percentage values were very similar: $0.95 \mu \mathrm{mol} \mathrm{g} \mathrm{FW}^{-1}$ and $94 \%$, respectively. Interestingly, in plants overexpressing Trx m, whereas the proportion of reduced GSH was not modified (93\%), the content, $0.75 \mu \mathrm{mol} \mathrm{g} \mathrm{FW}^{-1}$, was significantly lower $(c a .-20 \%)$ than in Wt and Trx $\mathrm{f}^{+}$plants (Figures 5A,B). Regarding ascorbate, both Wt and Trx $\mathrm{f}^{+}$plants display very similar total contents $\left(0.82\right.$ and $0.85 \mu \mathrm{nmol} \mathrm{g} \mathrm{FW}^{-1}$, respectively) and proportions of reduced form (83 and $86 \%$, respectively) in young well-expanded leaves (Figures 5C,D). In contrast, the total ascorbate content, $0.65 \mu \mathrm{nmol} \mathrm{g} \mathrm{FW}{ }^{-1}$, was significantly lower in $\operatorname{Tr} x \mathrm{~m}^{+}$plants, but with an unchanged redox status $(82 \%)$ compared to the two other lines (Figures 5C,D). Taken together, these data reveal that GSH and ascorbate pools are not altered when Trx $\mathrm{f}$ is overexpressed, but significantly and similarly modified in $\operatorname{Tr} \mathrm{m}^{+}$plants. Indeed, these plants exhibit a decrease of $c a .20 \%$ in the total content of ascorbate and GSH without any noticeable change in redox status.

\section{TOLERANCE TO PHOTOOXIDATIVE TREATMENT OF TOBACCO PLANTS OVEREXPRESSING Trx f OR Trx m}

Oxidative stress tolerance of transplastomic tobacco plants was monitored by exposing them to a treatment combining high light and low temperature, conditions known to generate loss of photosynthetic membranes within chloroplasts due to photooxidative damage. Thirty-day old plants grown in standard conditions were transferred to a light intensity of $950 \mu \mathrm{mol}$ photons $\mathrm{m}^{-2} \mathrm{~s}^{-1}$ at 


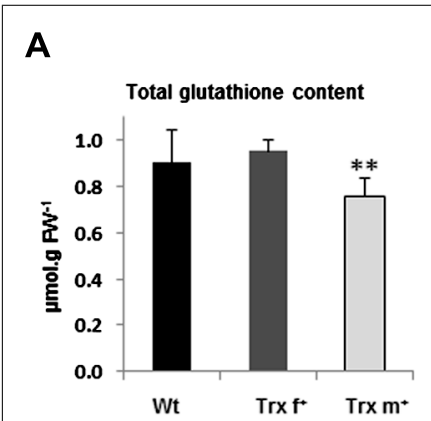

B

C
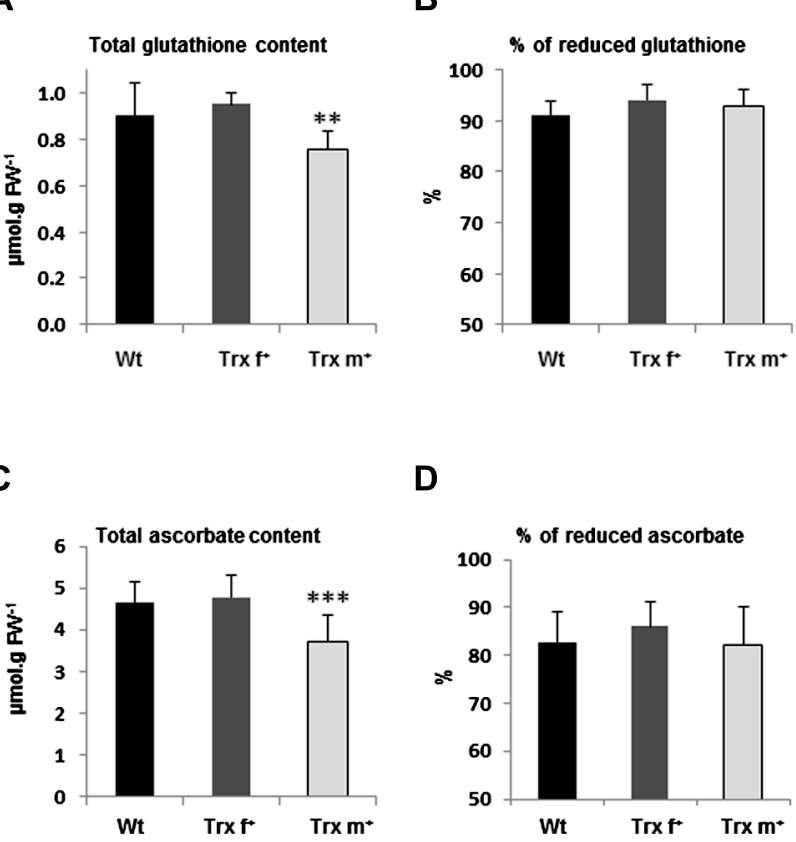

D

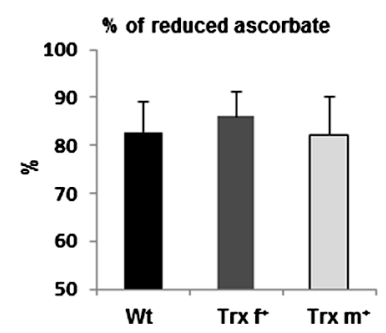

FIGURE 5 | Glutathione and ascorbate content in transplastomic tobacco plants overexpressing $\operatorname{Trx} \mathbf{f}$ or $\operatorname{Tr} \mathbf{m}$. Total content $(\mathbf{A}, \mathbf{C})$ and redox status (B, D) of glutathione $(\mathbf{A}, \mathbf{B})$ and ascorbate $(\mathbf{C}, \mathbf{D})$ were determined in leaves of tobacco plants grown in standard conditions for 40 days. Measurements were performed using HPLC as described in Section "Materials and Methods" using three 1-cm leaf disks from young well-expanded leaves. Data are mean values \pm SD from at least 10 independent measurements per genotype. Wt, wild-type; $\operatorname{Tr} x \mathrm{f}^{+}$and $\operatorname{Tr} \mathrm{x}$ $\mathrm{m}^{+}$, plants overexpressing $\operatorname{Tr} \mathrm{f}$ or $\operatorname{Tr} \mathrm{m}$, respectively. Values significantly different from Wt values with ${ }^{* *} p<0.01$ and ${ }^{* * *} p<0.001$ ( $t$-test).

$8^{\circ} \mathrm{C}$. After 1 day, some bleaching appeared particularly in wellexpanded and old leaves and damage intensity increased until the 4th day of treatment. Interestingly, a differential behavior was observed: Wt and Trx $\mathrm{f}^{+}$exhibited much larger bleached leaf areas compared to $\operatorname{Tr} \mathrm{x} \mathrm{m}^{+}$plants, which displayed damage limited to leaf edges (Figure 6A). To further investigate the responses of tobacco plants to photooxidative stress conditions, we measured maximal photosystem II efficiency, using the chlorophyll fluorescence parameter, $F_{\mathrm{v}} / F_{\mathrm{m}}$, which constitutes a sensitive indicator of photosynthetic performance and reveals whether photosynthetic structures are damaged (Maxwell and Johnson, 2000). As previously observed in control conditions (Figure 2), Wt and Trx $\mathrm{f}^{+}$ plants displayed close $F_{\mathrm{v}} / F_{\mathrm{m}}$ values, 0.785 and 0.754 , respectively, whereas this value was already substantially decreased in $\operatorname{Trx} \mathrm{m}^{+}$ plants $\left(0.691\right.$; Figure 6B). $F_{\mathrm{v}} / F_{\mathrm{m}}$ measurements in plants exposed to photooxidative treatment for a period of 5 days revealed a strong decrease in PSII photosynthetic efficiency in Wt and $\operatorname{Tr} \mathrm{f}^{+}$plants since the recorded values were reduced by $c a$. 65 and $70 \%(0.272$ and 0.233 , respectively). In contrast, the decrease observed in $\operatorname{Tr} x$ $\mathrm{m}^{+}$plants was much less pronounced, the mean $F_{\mathrm{v}} / F_{\mathrm{m}}$ value measured in this line being reduced by ca. $45 \%$ (0.371). These data reveal that photosynthetic efficiency is less impaired in $\operatorname{Tr} x$ $\mathrm{m}^{+}$plants exposed to photooxidative treatment and are consistent with the visual observations of limited leaf bleaching in this line.

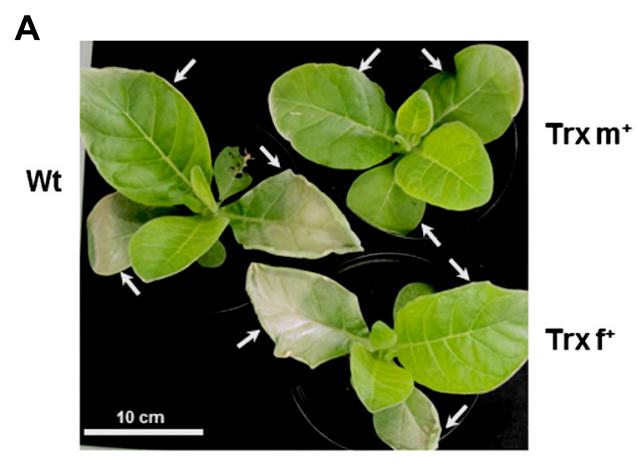

B

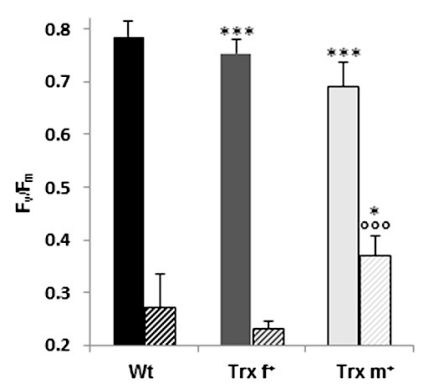

FIGURE 6 | Tolerance to photooxidative treatment of transplastomic tobacco plants overexpressing Trx f or Trx $\mathbf{m}$. Photooxidative treatment was carried out by exposing 30-old tobacco plants grown in standard conditions to high light intensity $\left(950 \mu \mathrm{mol}\right.$ photons $\left.\mathrm{m}^{-2} \mathrm{~s}^{-1}\right)$ and low temperature $\left(8^{\circ} \mathrm{C}\right)$ under a $12-\mathrm{h}$ photoperiod in a controlled growth chamber. (A) Photograph showing representative plants subjected to the treatment for 5 days. Three independent experiments were carried out with three plants per genotype in each experiment. (B) Maximal photosystem II photochemical efficiency in tobacco plants. $F_{\mathrm{v}} / F_{\mathrm{m}}$ values were measured in plants grown in control conditions for 32 days (full bars) and in plants further subjected to photooxidative conditions for 5 days (dashed bars). Data are mean values \pm SD of the average values from eight measurements performed on five plants per genotype. Measurements were performed on representative areas from three leaves (indicated by arrows in panel A) per plant. Wt, wild-type; $\operatorname{Tr} x \mathrm{f}^{+}$and $\operatorname{Tr} \mathrm{x} \mathrm{m}^{+}$, plants overexpressing $\operatorname{Trx} f$ or $\operatorname{Tr} x \mathrm{~m}$, respectively. Values significantly different from Wt values with ${ }^{*} p<0.05$ and ${ }^{*}{ }^{*} p<0.001$ ( $t$-test); ${ }^{\circ}$ o Value significantly different from the $\operatorname{Tr} x \mathrm{f}^{+}$value with $p<0.001$ (t-test).

\section{TOLERANCE TO METHYL VIOLOGEN OF TOBACCO PLANTS OVEREXPRESSING Trx f OR Trx m}

Trx overexpressing plants were also evaluated for protection against damage induced by $\mathrm{MV}$, a redox-cycling herbicide that generates superoxide radicals by accepting electrons from PSI and transferring them to oxygen (Babbs et al., 1989). MV-mediated oxidative damage was assessed in whole plants sprayed with $\mathrm{MV}$, and visual symptoms were registered 2 days following treatment. Wt and $\operatorname{Trx} \mathrm{f}^{+}$plants were severely affected by MV treatment, whereas necrotic lesions were more limited in $\operatorname{Trx} \mathrm{m}^{+}$plants (Figure 7A and data not shown). Maximal PSII efficiency $\left(F_{\mathrm{v}} / F_{\mathrm{m}}\right)$ was measured $5 \mathrm{~h}$ after MV treatment. Similarly to the results reported above for photooxidative damage, PSII photosynthetic efficiency was significantly impaired in Wt and Trx $\mathrm{f}^{+}$plants ( $F_{\mathrm{v}} / F_{\mathrm{m}}$ values reduced by $c a .20$ and $40 \%$, respectively), whereas almost no change was observed in $\operatorname{Trx} \mathrm{m}^{+}$plants (Figure 7B). To further evaluate the tolerance of transplastomic tobacco plants to 


\section{A}

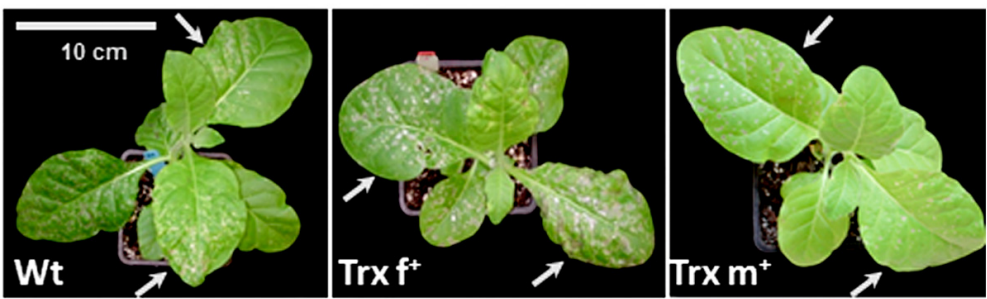

B

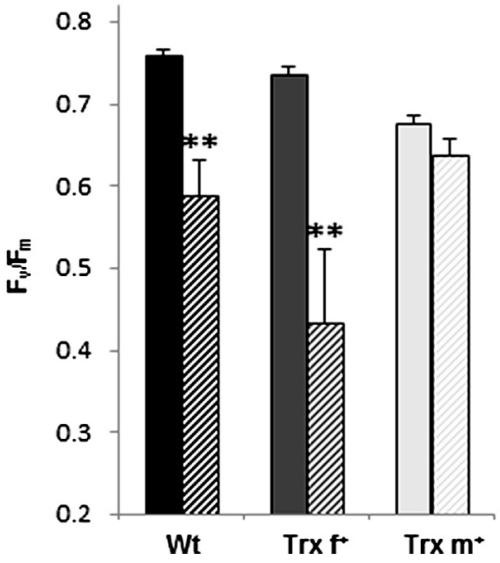

C

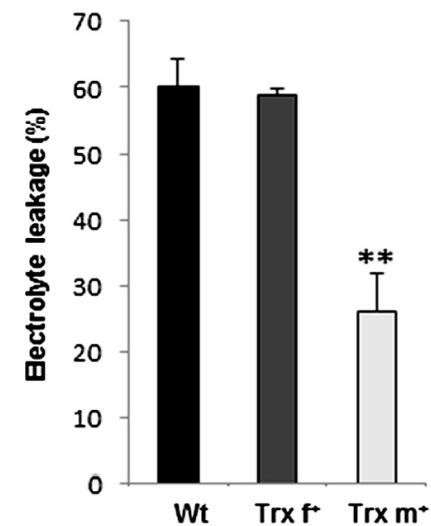

FIGURE 7 | Tolerance to methyl viologen of transplastomic tobacco plants overexpressing Trx f or Trx m. 40-day old tobacco plants were sprayed with $30 \mu \mathrm{M} \mathrm{MV}$ and grown in a controlled growth chamber as described in Section "Materials and Methods." (A) Visual symptoms 2 days after treatment. Photographs show representative plants subjected to the treatment. (B) Maximal photosystem II photochemical efficiency in tobacco plants. $F_{\mathrm{v}} / F_{\mathrm{m}}$ values were measured in plants grown in control conditions (full bars) and in plants subjected to MV treatment for $5 \mathrm{~h}$ (dashed bars). Data are mean values \pm SD from six plants per genotype. Measurements were performed on two leaves (indicated by arrows in panel A) per plant. ${ }^{*}$ Value significantly different from the value measured in relative non-treated plants with $p<0.01$ ( $t$-test). (C) Electrolyte leakage measured on tobacco leaf disks after incubation on $1 \mu \mathrm{M} \mathrm{MV}$ for $14 \mathrm{~h}$ at $600 \mu \mathrm{mol}$ photons $\mathrm{m}^{-2} \mathrm{~s}^{-1}$. Results were expressed as the percentage of total electrolytes released after treatment relative to that of disks incubated on water under the same conditions. Data are mean values \pm SD from three assays. Wt, wild-type; $T r x$ $\mathrm{f}^{+}$and $\operatorname{Tr} \mathrm{x} \mathrm{m}^{+}$, plants overexpressing $\operatorname{Tr} x \mathrm{f}$ or $\operatorname{Tr} x \mathrm{~m}$, respectively.

** Significantly different from Wt with $p<0.01$ ( $t$-test).
MV, membrane damage was estimated by measuring ion release from control and treated leaf disks. Following incubation on MV, the level of electrolyte leakage from $\operatorname{Trx} \mathrm{f}^{+}$disks was relatively high and comparable to that of Wt (ca. $60 \%$ of the total electrolyte content, Figure 7C). In contrast, plants overexpressing Trx $\mathrm{m}$ displayed a much lower level of ion release (25\%). Altogether, these results signify that overexpression of $\operatorname{Trx} m$, but not of $\operatorname{Trx} f$, increases tolerance to MV.

\section{DISCUSSION}

\section{SPECIFICITY OF Trx m FUNCTION}

In contrast to other organisms, where only two or three multifunctional Trx isoforms are present (Ritz et al., 2000; Garrido and Grant, 2002), plants display a great diversity of Trxs with physiological functions remaining elusive for many of them. Our work based on a genetic strategy contributes to decipher the role of Trx $\mathrm{m}$ in planta. Clear differences have been observed between plants overexpressing either $\operatorname{Trx} \mathrm{m}$ or $\operatorname{Tr} \mathrm{f}$. $\operatorname{Tr} \mathrm{m} \mathrm{m}^{+}$plants exhibit reduced growth and impaired photosynthesis (Figures 1,2), but increased tolerance to oxidative treatments (Figures 6,7). In comparison, $\operatorname{Tr} x$ $\mathrm{f}^{+}$plants are almost undistinguishable from $\mathrm{Wt}$, in full agreement with previous data (Sanz-Barrio et al., 2013) and others gained in Arabidopsis mutants knockout for Trx f (Thormählen et al., 2013) and in Trx f RNAi pea plants (Luo et al., 2012). Consistently, in heterologous complementation assays in yeast, Arabidopsis Trx m, but not $\operatorname{Trx} \mathrm{f}$, confers tolerance to oxidative stress (Issakidis-Bourguet et al., 2001). Taken together, these reports indicate that Trxs $f$ and $\mathrm{m}$ fulfill distinct and non-overlapping physiological functions very likely through a marked specificity towards their targets in planta.

In the last years, knowledge has been acquired about the essential roles of some plant Trxs, particularly plastidial isoforms. Some are critical such as $\operatorname{Trx} \mathrm{z}$ which is needed for plastid development and seedling viability (Arsova et al., 2010). NTRC-KO Arabidopsis plants display pale phenotype, impaired photosynthesis and sensitivity to oxidative stress, high temperature and prolonged darkness (Pérez-Ruiz et al., 2006; Lepistö et al., 2009; Chae et al., 2013). Other plastidial Trxs play more specialized functions such as CDSP32, which prevents oxidative damage during environmental constraints (Broin et al., 2002; Rey et al., 2005) and Trx y2, which maintains growth under high light conditions (Laugier et al., 2013). In other respects, cytosolic Trx h1 participates in responses to salt treatment (Zhang et al., 2011) and Trx h5 in sensitivity 
to a fungal toxin (Sweat and Wolpert, 2007). Our present work reveals that $\operatorname{Trx} \mathrm{m}$ fulfills essential functions in photosynthetic processes and in stress tolerance. Noteworthy, down-regulation of Trx m gene expression in rice also leads to impaired growth and reduced chlorophyll content in control conditions (Chi et al., 2008). This further argues for a function of $\operatorname{Trx} m$ as a central actor controlling photosynthesis. However, no obvious phenotype was recorded in Arabidopsis mutants deficient for either $\operatorname{Tr} \mathrm{x} \mathrm{m} 1$ or $\operatorname{Tr} \mathrm{x}$ m4 (Courteille et al., 2013; Laugier et al., 2013). Since these Trxs share, with $\operatorname{Trx} \mathrm{m} 2$, very similar sequence and biochemical properties (Collin et al., 2003), we hypothesize that the three isoforms could play overlapping functions in Arabidopsis.

\section{PHENOTYPE OF TrX $\mathrm{m}^{+}$TOBACCO UNDER CONTROL CONDITIONS}

Compared to Wt and $\operatorname{Trx} \mathrm{f}^{+}$plants, $\operatorname{Trx} \mathrm{m}^{+}$plants grown in control conditions display modified chlorophyll composition and impaired PSII activity (Figure 2; Table 1). Trx m overexpression in tobacco (Table 1), like Trx m deficiency in rice (Chi et al., 2008), leads to lower chlorophyll content and increased $\mathrm{Chl} a / \mathrm{Chl} b$ ratio. Luo et al. (2012) showed that pea plants silenced for both genes encoding Trxs $\mathrm{f}$ and $\mathrm{m}$ exhibit reduced chlorophyll content and a much higher level of the oxidized form of CHLI, a subunit of magnesium chelatase, an enzyme essential for chlorophyll biosynthesis and regulated by Trxs (Ikegami et al., 2007). Moreover, Luo et al. (2012) reported that the expression of numerous genes involved in tetrapyrole biosynthesis was also strongly altered in these pea plants. Therefore, we can hypothesize that expression and redox activation of enzymes participating in chlorophyll synthesis are modified in $\operatorname{Trx} \mathrm{m}^{+}$tobacco due to the large Trx excess, leading to change in pigment content. In other respects, one LHCII protein has been identified as a Trx target in spinach thylakoid membranes (Balmer et al., 2006). Interestingly in Trx $\mathrm{m}^{+}$plants, we recorded a much lower content in Chl $b$ (Table 1), which is more specifically associated with LHC proteins, and preliminary proteomic analyses on transplastomic lines indicate that LHCII proteins are less abundant compared to Wt and Trx $\mathrm{f}^{+}$(unpublished data). All these data prompt us to propose that Trx m might be involved in the regulation of the light capture process via the control of the abundance and/or redox status of LHC proteins. We previously reported that Trx $\mathrm{m}^{+}$plants are characterized by the absence of cyclic electron transfer via the NDH pathway (Courteille et al., 2013). Thus, the suppression of this pathway might modify the NADPH/ATP ratio within plastids and finally impair the whole photosynthetic process. This hypothesis is not supported by the fact that tobacco plants knockout for the whole NDH complex do not exhibit any noticeable phenotype in control conditions (Horváth et al., 2000). Nonetheless, as the other cyclic electron pathway via the proton gradient regulation (PGR) complex is also negatively regulated by Trx m4 in in vitro experiments (Courteille et al., 2013), we cannot exclude that inhibition of both cyclic NDH and PGR pathways due to high Trx $m$ abundance results in substantial impairment of photosynthetic processes. In other respects, in control conditions no obvious difference between the two transplastomic lines has been noticed regarding the activities in leaf extracts of two enzymes involved in carbon metabolism, NADP-MDH and NADP-GAPDH (Figure 3). Based on all these data, we conclude that the phenotype of $\operatorname{Trx~} \mathrm{m}^{+}$plants is probably not linked to changes in carbon metabolism, but more likely to modifications in photochemical processes from light capture to electron transfer.

Interestingly, plants overexpressing Trx m display reduced contents in ascorbate and GSH (ca. $-20 \%$ compared to Wt and Trx $\mathrm{f}^{+}$plants), with no modification in redox status (Figure 5). This reveals that $\operatorname{Trx} m$ exerts a specific control on the amount of these compounds through mechanisms remaining to be delineated. Regarding AsA, redox regulation of enzymes involved in biosynthesis and regeneration pathways could account for the modified content. Indeed, dehydroascorbate reductase (DHAR), the enzyme regenerating AsA from its oxidized form, has been identified as a Trx target in several reports (Marchand et al., 2004; Hägglund et al., 2008; Montrichard et al., 2009) and reduction of DHAR by Trx is known to activate the enzyme (Dixon et al., 2002). Consequently, overexpression of $\operatorname{Tr} \mathrm{m}$ in tobacco might trigger activation of DHAR and lead to increased AsA recycling, thus explaining the need for a reduced pool of AsA in Trx $\mathrm{m}^{+}$tobacco. But note that in tobacco plants overexpressing DHAR, increased AsA recycling is associated with increased AsA content (Chen et al., 2003). Currently, there is no evidence for a possible redox regulation of enzymes involved in GSH metabolism (Montrichard et al., 2009). It is worth mentioning that the increase in AsA content due to DHAR overexpression in tobacco plants is accompanied by a GSH pool increased in the same range (Chen et al., 2003). Further studies are needed to investigate whether the decreased GSH content in $\operatorname{Trx} \mathrm{m}^{+}$plants is linked to modified AsA level or is a direct consequence of Trx overexpression. Whether the modified GSH and AsA pools in Trx $\mathrm{m}^{+}$plants lead to the observed growth and photosynthesis phenotype remains also unclear. Nonetheless, these data unveil a new role for Trx $\mathrm{m}$ in plant cell redox homeostasis through regulation of the content in major soluble antioxidants.

\section{PHENOTYPE OF Trx $\mathrm{m}^{+}$TOBACCO UNDER OXIDATIVE TREATMENTS}

Compared to $\mathrm{Wt}$ and to $\operatorname{Trx} \mathrm{f}^{+}, \operatorname{Trx} \mathrm{m}^{+}$plants are more tolerant to conditions generating oxidative damage, induced by either MV or high light combined to low temperature (Figures 6,7), revealing a role of $\operatorname{Trx} \mathrm{m}$ in the protection of plastidial structures. Accordingly, the abundance of Trx $\mathrm{m} 1$ is strongly up-regulated in cold-stressed Arabidopsis plants and this Trx has been proposed to preserve photosynthetic apparatus (Goulas et al., 2006). The tolerance of $\operatorname{Trx~} \mathrm{m}^{+}$plants is nonetheless rather puzzling when taking into consideration their reduced chlorophyll content (by more than $40 \%$ for $\mathrm{Chl} b$ ) since an Arabidopsis mutant lacking $\mathrm{Chl} b$ is much more sensitive to photooxidative treatments, partly due to increased single oxygen production (Dall'Osto et al., 2010). Thus, the tolerance of $\operatorname{Trx} \mathrm{m}^{+}$tobacco plants is not directly linked to chlorophyll content, but to other mechanisms also counterbalancing the deleterious effects due to $\mathrm{Chl} b$ shortage. Based on our data, we presume that neither NPQ, nor soluble antioxidants constitute primary determinants in this stress tolerance. Indeed, in $\operatorname{Trx} \mathrm{m}^{+}$ plants, NPQ is not modified (Figure 2) and both AsA and GSH pools are reduced by $c a$. $20 \%$ (Figure 5), with no change in redox status. In numerous cases, there is a positive correlation between stress tolerance level and AsA content. For instance, an Arabidopsis mutant deficient in AsA is highly sensitive to environmental constraints (Conklin et al., 1996) and tobacco plants with increased 
AsA content are more tolerant to high light (Chen and Gallie, 2008). Regarding GSH, as reviewed very recently (Zagorchev et al., 2013), complex and contradictory data have been reported since tobacco plants with decreased GSH reductase activity are more sensitive to oxidative stress (Ding et al., 2009), but plants displaying elevated GSH biosynthesis capacity show high sensitivity to light (Creissen et al., 1999).

$\operatorname{Trx} \mathrm{m}^{+}$plants display reduced PSII activity in control conditions (Figure 2), and surprisingly this activity is much less affected under oxidative conditions compared to Wt (Figures 6,7). Exposure to environmental constraints generally impairs PSII at the D1 protein level due to increased production of reactive oxygen species and inhibits PSII repair via the suppression of the synthesis of this subunit (Takahashi and Murata, 2008). Thus we can speculate that the excess of Trx $m$ is associated with preservation of PSII structures in stress conditions. In connection with this hypothesis, it is worth mentioning that $\operatorname{Trx}$ has been proposed to regulate D1 synthesis as a function of light level (Danon and Mayfield, 1994).

Finally, we can hypothesize that the tolerance of $\operatorname{Trx} \mathrm{m}^{+}$plants results from direct prevention by Trx $m$ of damage in the photosynthetic apparatus. We recently reported that both plastidial Trxs $\mathrm{f}$ and $\mathrm{m}$ are able to form oligomers possessing chaperonelike properties (Sanz-Barrio et al., 2012). However, since there is a differential behavior of $\operatorname{Trx} \mathrm{m}^{+}$and $\mathrm{f}^{+}$plants exposed to oxidative treatments, it appears unlikely that such a function could specifically account for the phenotype of $\operatorname{Trx} \mathrm{m}^{+}$plants. In other respects, their stress tolerance could originate also from increased electron supply to Trx targets participating in antioxidant mechanisms, thus improving the plant capacity to adapt to challenging environmental conditions. Prxs are not likely involved in such a process since no noticeable difference was observed in

\section{REFERENCES}

Arnér, E. S. J., and Holmgren, A. (2000). Physiological functions of thioredoxin and thioredoxin reductase. Eur. J. Biochem. 267, 61026109. doi: 10.1046/j.1432-1327.2000. 01701.x

Arsova, B., Hoja, U., Wimmelbacher, M., Greiner, E., Ustün, S., Melzer, M., et al. (2010). Plastidial thioredoxin $\mathrm{z}$ interacts with two fructokinaselike proteins in a thiol-dependent manner: evidence for an essential role in chloroplast development in Arabidopsis and Nicotiana benthamiana. Plant Cell 22, 1498-1515. doi: 10.1105/tpc.109.071001

Babbs, C. F., Pham, J.,A., and Coolbaugh, R. C. (1989). Lethal hydroxyl radical production in paraquat-treated plants. Plant Physiol. 90, 1267-1270. doi: 10.1104/pp.90.4.1267

Balmer, Y., Vensel, W. H., Hurkman, W. J., and Buchanan, B. B. (2006). Thioredoxin target proteins in chloroplast thylakoid membranes. Antioxid. Redox Signal. 8, 1829-1834. doi: 10.1089/ars.2006.8.1829
Benitez-Alfonso, Y., Cilia, M., San Roman, A., Thomas, C., Maule, A., Hearn, S., et al. (2009). Control of Arabidopsis meristem development by thioredoxin-dependent regulation of intercellular transport. Proc. Natl. Acad. Sci. U.S.A. 106, 3615-3620. doi: 10.1073/pnas.0808717106

Bouchenak, F., Henri, P., Benrebiha, F. Z., and Rey, P. (2012). Differential responses to salinity of two Atriplex halimus populations in relation to organic solutes and antioxidant systems involving thiol reductases. J. Plant Physiol. 169, 1445-1553. doi: 10.1016/j.jplph.2012.06.009

Broin, M., Cuiné, S., Eymery, F., and Rey, P. (2002). The plastidic 2-Cys peroxiredoxin is a target for a thioredoxin involved in the protection of the photosynthetic apparatus against oxidative damage. Plant Cell 14, 1417-1432. doi: 10.1105/tpc.001644

Chae, H. B., Moon, J. C., Shin, M. R., Chi, Y. H., Jung, Y. J., Lee, S. Y., et al. (2013). Thioredoxin reductase type $\mathrm{C}$ (NTRC) orchestrates enhanced thermotolerance to Arabidopsis by its redox-dependent holdase chaperone

abundance and/or redox status of the main plastidial Prxs in Trx $\mathrm{m}^{+}$plants (Figure 4). In contrast, we observed a twice higher MSR enzymatic capacity in $\operatorname{Trx} \mathrm{m}^{+}$plants than in $\operatorname{Trx} \mathrm{f}^{+}$and Wt plants with no change in protein abundance (Figure 4). This signifies that $\operatorname{Trx} \mathrm{m}$ very likely constitutes a physiological electron donor to MSRs. This is consistent with our previous work showing that while MSR capacity is slightly lowered in Arabidopsis plants deficient for $\operatorname{Tr} \mathrm{f}$, it is significantly reduced in mutants lacking various Trx m types (Laugier et al., 2013). MSRs are key enzymes repairing oxidized proteins and possibly scavenging ROS via MetO (Moskovitz et al., 1997). In plants, they are involved in the protection against environmental constraints (Romero et al., 2004; Laugier et al., 2010) and in seed longevity (Châtelain et al., 2013). Altogether, these data give high credence for a role of the Trx m/MSR system in the tolerance of $\operatorname{Trx} \mathrm{m}^{+}$plants to oxidative treatments.

To conclude, the complex phenotype of transplastomic tobacco $\operatorname{Trx} \mathrm{m}^{+}$plants indicates that this Trx is very likely a central actor in plant cell redox homeostasis. In contrast to other types like $\mathrm{f}$, the $\mathrm{m}$ type could regulate in planta numerous redox-based processes in photosynthesis and antioxidant responses. Further investigations, based for instance on co-immunoprecipitation methods to isolate Trx m partners in plant extracts (Rey et al., 2005), are needed to unveil the target proteins and the mechanisms underlying the physiological function(s) of this Trx type.

\section{ACKNOWLEDGMENTS}

We are very grateful to $\mathrm{P}$. Henri for valuable assistance in growing tobacco plants and to the Groupe de Recherche Appliquée en Phytotechnologie (CEA, IBEB, SBVME, GRAP) for technical assistance with controlled growth chambers.

function. Mol. Plant 6, 323-336. doi: $10.1093 / \mathrm{mp} / \mathrm{sss} 105$

Châtelain, E., Satour, P., Laugier, E., Ly Vu, B., Payet, N., Rey, P., et al. (2013). Evidence for the participation of the methionine sulfoxide reductase repair system in plant seed longevity. Proc. Natl. Acad. Sci. U.S.A. 110, 3633-3638. doi: 10.1073/pnas. 1220589110

Chen, Z., and Gallie, D. R. (2008). Dehydroascorbate reductase affects non-photochemical quenching and photosynthetic performance. J. Biol. Chem. 283, 21347-21361. doi: 10.1074/jbc.M802601200

Chen, Z., Young, T. E., Ling, J., Chang, S. C., and Gallie, D. R. (2003). Increasing vitamin $C$ content of plants through enhanced ascorbate recycling. Proc. Natl. Acad. Sci. U.S.A. 100, 3525-3230. doi: 10.1073/pnas.0635176100

Chi, Y. H., Moon, J. C., Park, J. H., Kim, H. S., Zulfugarov, I. S., Fanata, W. I., et al. (2008). Abnormal chloroplast development and growth inhibition in rice thioredoxin m knock-down plants. Plant Physiol.
148, 808-817. doi: 10.1104/pp.108. 123547

Collin, V., Eymery, F., Genty, B., Rey, P., and Havaux, M. (2008). Vitamin E plays a crucial role in the tolerance of Arabidopsis thaliana to oxidative stress induced by heavy metals. Plant Cell Environ. 31, 244-257.

Collin, V., Issakidis-Bourguet, E., Marchand, C., Hirasawa, M., Lancelin, J. M., Knaff, D. B., et al. (2003). The Arabidopsis plastidial thioredoxins: new functions and new insights into specificity. J. Biol. Chem. 278, 23747-23752. doi: 10.1074/jbc. M302077200

Collin, V., Lamkemeyer, P., MiginiacMaslow, M., Hirasawa, M., Knaff, D. B., Dietz, K. J., et al. (2004). Characterization of plastidial thioredoxins from Arabidopsis belonging to the new y-type. Plant Physiol. 136, 40884095. doi: 10.1104/pp.104.052233

Conklin, P. L., Williams, E. H., and Last, R. L. (1996). Environmental stress sensitivity of an ascorbic aciddeficient Arabidopsis mutant. Proc. Natl. Acad. Sci. U.S.A. 93, 9970-9974. doi: $10.1073 /$ pnas.93.18.9970 
Courteille, A., Vesa, S, Sanz-Barrio, R., Cazalé-Noël, A. C., Becuwe-Linka, N., Farran, I., et al. (2013). Thioredoxin $\mathrm{m} 4$ controls photosynthetic alternative electron pathways in Arabidopsis. Plant Physiol. 161, 508-520. doi: 10.1104/pp.112.207019

Creissen, G., Firmin, J., Fryer, M., Kular, B., Leyland, N., Reynolds, H., et al. (1999). Elevated glutathione biosynthetic capacity in the chloroplasts of transgenic tobacco plants paradoxically causes increased oxidative stress. Plant Cell 11, 1277-1292.

Dall'Osto, L., Cazzaniga, S., Havaux, M., and Bassi, R. (2010). Enhanced photoprotection by protein-bound vs free xanthophyll pools: a comparative analysis of chlorophyll $b$ and xanthophyll biosynthesis mutants. Mol. Plant 3, 576-593. doi: $10.1093 / \mathrm{mp} / \mathrm{ssp} 117$

Danon, A., and Mayfield, S. P. (1994). Light-regulated translation of chloroplast messenger RNAs through redox potential. Science 266, 1717-1719. doi: 10.1126/science.7992056

Dietz, K. J. (2011). Peroxiredoxins in plants and cyanobacteria. Antioxid. Redox Signal. 15, 1129-1159. doi: 10.1089/ars.2010.3657

Ding, S., Lu, Q., Zhang, Y., Yang, Z., Wen, X., Zhang, L., et al. (2009). Enhanced sensitivity to oxidative stress in transgenic tobacco plants with decreased glutathione reductase activity leads to a decrease in ascorbate pool and ascorbate redox state. Plant Mol. Biol. 69, 577-592. doi: 10.1007/s11103-008-9440-3

Dixon, D. P., Davis, B. G., and Edwards, R. (2002). Functional divergence in the glutathione transferase superfamily in plants. Identification of two classes with putative functions in redox homeostasis in Arabidopsis thaliana. J. Biol. Chem. 277, 30859 30869. doi: 10.1074/jbc.M202919200

Garrido, E. O., and Grant, C. M. (2002). Role of thioredoxins in the response of Saccharomyces cerevisiae to oxidative stress induced by hydroperoxides. Mol. Microbiol. 43, 993-1003. doi: 10.1046/j.1365-2958.2002.02795.x

Goulas, E., Schubert, M., Kieselbach, T., Kleczkowski, L. A., Gardeström, P., Schröder, W., et al. (2006). The chloroplast lumen and stromal proteomes of Arabidopsis thaliana show differential sensitivity to short- and long-term exposure to low temperature. Plant J. 47, 720-734. doi: 10.1111/j.1365-313X.2006.02821.x

Hägglund, P., Bunkenborg, J., Maeda, K., and Svensson, B. (2008). Identification of thioredoxin disulfide targets using a quantitative proteomics approach based on isotope-coded affinity tags. J. Proteome Res. 7, 52705276. doi: 10.1021/pr800633y

Havaux, M., Bonfils, J. P., Lütz, C. and Niyogi, K. K. (2000). Photodamage of the photosynthetic apparatus and its dependence on the leaf developmental stage in the npql Arabidopsis mutant deficient in the xanthophyll cycle enzyme violaxanthin de-epoxidase. Plant Physiol. 124, 273-284. doi: 10.1104/pp.124.1.273

Havaux, M., Eymery, F., Porfirova, S., Rey P., and Dörmann, P. (2005). Vitamin E protects against photoinhibition and photoxidative stress in Arabidopsis thaliana. Plant Cell 17, 3451-3469. doi: 10.1105/tpc.105. 037036

Horváth, E. M., Peter, S. O., Joët, T., Rumeau, D., Cournac, L., Horváth, G. V., et al. (2000). Targeted inactivation of the plastid ndhB gene in tobacco results in an enhanced sensitivity of photosynthesis to moderate stomatal closure. Plant Physiol. 123, 1337-1350. doi: 10.1104/pp.123.4.1337

Ikegami, A., Yoshimura, N., Motohashi, K., Takahashi, S., Romano, P. G. N., Hisabori, T., et al. (2007). The CHLI1 subunit of Arabidopsis thaliana magnesium chelatase is a target protein of the chloroplast thioredoxin. J. Biol. Chem. 282, 19282-19291. doi: 10.1074/jbc.M703324200

Issakidis-Bourguet, E., Mouaheb, N., Meyer, Y., and Miginiac-Maslow, M. (2001). Heterologous complementation of yeast reveals a new putative function for chloroplast m-type thioredoxin. Plant J. 25, 127-136. doi: 10.1046/j.0960-7412.2000.00943.x

Jacquot, J. P., Rivera-Madrid, R., Marinho, P., Kollarova, M., Le Maréchal, P., Miginiac-Maslow, M., et al. (1994). Arabidopsis thaliana NADPH thioredoxin reductase. cDNA characterization and expression of the recombinant protein in Escherichia coli. J. Mol. Biol. 235, 1357-1363. doi: 10.1006/jmbi.1994.1091

Jacquot, J. P., Vidal, J., Gadal, P., and Schürmann, P. (1978). Evidence for the existence of several enzymespecific thioredoxins in plants. FEBS Lett. 96, 243-246. doi: 10.1016/00145793(78)80410-4

Keryer, E., Collin, V., Lavergne, D., Lemaire, S. D., and IssakidisBourguet, E. (2004). Characterization of Arabidopsis T-DNA mutants for the variable subunit of ferredoxin: thioredoxin reductase. Photosynth. Res. 79, 265-274. doi: 10.1023/ B:PRES.0000017173.46185.3e

Kobrehel, K., Wong, J. H., Balogh, A., Kiss, F., Yee, B. C., and Buchanan, B. B. (1992). Specific reduction of wheat storage proteins by thioredoxin h. Plant Physiol. 99, 919-924. doi: 10.1104/pp.99.3.919

Laugier, E., Tarrago, L., Courteille, A., Innocenti, G., Eymery, F., Rumeau, D., et al. (2013). Involvement of thioredoxin $\mathrm{y} 2$ in the preservation of leaf methionine sulfoxide reductase capacity and growth under high light. Plant Cell Environ. 36, 670-682. doi: 10.1111/pce. 12005

Laugier, E., Tarrago, L., Vieira Dos Santos, C., Eymery, F., Havaux, M., and Rey, P. (2010). Arabidopsis thaliana plastidial methionine sulfoxide reductases B, MSRBs, account for most leaf peptide MSR activity and are essential for growth under environmental constraints through a role in the preservation of photosystem antennae. Plant J. 61, 271-282. doi: 10.1111/j.1365-313X.2009.04053.x

Lemaire, S. D., Michelet, L., Zaffagnini, M., Massot, V., and IssakidisBourguet, E. (2007). Thioredoxins in chloroplasts. Curr. Genet. 51, 343365. doi: 10.1007/s00294-007-0128-z

Lepistö, A., Kangasjärvi, S., Luomala, E. M., Brader, G., Sipari, N., Keränen, M., et al. (2009). Chloroplast NADPH-thioredoxin reductase interacts with photoperiodic development in Arabidopsis. Plant Physiol. 149, 1261-1276. doi: 10.1104/pp.108.133777

Lichtenthaler, H. (1987). Chlorophylls and carotenoids: pigments of photosynthetic membranes. Methods Enzymol. 148, 350-382. doi: 10.1016/0076-6879(87)48036-1

Luo, T., Fan, T., Liu, Y., Rothbart, M., Yu, J., Zhou, S., et al. (2012). Thioredoxin redox-regulates ATPase activity of $\mathrm{Mg}$ chelatase CHLI subunit and modulates redox-mediated signaling in tetrapyrrole biosynthesis and homeostasis of reactive oxygen species in pea plants. Plant Physiol. 159, 118 130. doi: 10.1104/pp.112.195446

Marchand, C., Le Maréchal, P., Meyer, Y., Miginiac-Maslow, M., Issakidis-Bourguet, E., and Decottignies, P. (2004). New targets of Arabidopsis thioredoxins revealed by proteomic analysis. Proteomics 4 2696-2706. doi: 10.1002/pmic.20040 0805

Marok, M. A., Tarrago, L., Ksas, B., Henri, P., Abrous-Belbachir, O., Havaux, M., et al. (2013). A drought-sensitive barley variety displays oxidative stress and strongly increased contents in low-molecular weight antioxidant compounds during water deficit compared to a tolerant variety. J. Plant Physiol. 170, 633-645. doi: 10.1016/j.jplph.2012. 12.008
Marri, L., Zaffagnini, M., Collin, V., Issakidis-Bourguet, E., Lemaire, S. D., Pupillo, P., et al. (2009). Prompt and easy activation by specific thioredoxins of calvin cycle enzymes of Arabidopsis thaliana associated in the GAPDH/CP12/PRK supramolecular complex. Mol. Plant 2, 259-269. doi: $10.1093 / \mathrm{mp} / \mathrm{ssn} 061$

Maxwell, K., and Johnson, G. N. (2000). Chlorophyll fluorescence-a practical guide. J. Exp. Bot. 51, 659-668. doi: 10.1093/jexbot/51.345.659

Meng, L., Wong, J. H., Feldman, L. J., Lemaux, P. G., and Buchanan, B. B. (2010). A membrane-associated thioredoxin required for plant growth moves from cell to cell, suggestive of a role in intercellular communication. Proc. Natl. Acad. Sci. U.S.A. 107, 3900-3905. doi: 10.1073/pnas.0913759107

Meyer, Y., Reichheld, J. P., and Vignols, F. (2005). Thioredoxins in Arabidopsis and other plants. Photosynth. Res. 86, 419-433. doi: 10.1007/s11120005-5220-y

Montrichard, F., Alkhalfioui, F., Yano, H., Vensel, W. H., Hurkman, W. J., and Buchanan, B. B. (2009). Thioredoxin targets in plants: the first 30 years. J. Proteomics 72, 452-474. doi: 10.1016/j.jprot.2008.12.002

Moskovitz, J., Berlett, B. S., Poston, J. M., and Stadtman, E. R. (1997). The yeast peptide-methionine sulfoxide reductase functions as an antioxidant in vivo. Proc. Natl. Acad. Sci. U.S.A. 94, 9585-9589. doi: 10.1073/pnas.94.18.9585

Navrot, N., Collin, V., Gualberto, J., Gelhaye, E., Hirasawa, M., Rey, P., et al. (2006). Plant glutathione peroxidases are functional peroxiredoxins distributed in several subcellular compartments and regulated during biotic and abiotic stresses. Plant Physiol. 142, 1364-1379. doi: 10.1104/pp.106.089458

Née, G., Zaffagnini, M., Trost, P., and Issakidis-Bourguet, E. (2009). Redox regulation of chloroplastic glucose-6-phosphate dehydrogenase: a new role for f-type thioredoxin. FEBS Lett. 583, 2827-2832. doi: 10.1016/i.febslet.2009.07.035

Noctor, G., and Foyer, C. H. (1998). Ascorbate and glutathione: keeping active oxygen under control. Annu. Rev. Plant Physiol. Plant Mol. Biol. 49, 249-279. doi: 10.1146/annurev.arplant.49.1.249

Pérez-Ruiz, J. M., Spínola, M. C., Kirchsteiger, K., Moreno, J., Sahrawy, M., and Cejudo, F. J. (2006). Rice NTRC is a high-efficiency redox system for chloroplast protection against oxidative damage. 
Plant Cell 18, 2356-2368. doi: 10.1105/tpc.106.041541

Rey, P., Bécuwe, N., Barrault, M. B., Rumeau, D., Havaux, M., Biteau, B., et al. (2007). The Arabidopsis thaliana sulfiredoxin is a plastidic cysteinesulfinic acid reductase involved in photooxidative stress response. Plant J. 49, 505-514. doi: 10.1111/j.1365313X.2006.02969.x

Rey, P., Cuiné, S., Eymery, F., Garin, J., Court, M., Jacquot, J. P., et al. (2005). Analysis of the proteins targeted by CDSP32, a plastidic thioredoxin participating in oxidative stress responses. Plant J. 41, 31-42. doi: 10.1111/j.1365-313X.2004.02271.x

Rey, P., Pruvot, G., Becuwe, N., Eymery, F., Rumeau, D., and Peltier, G. (1998). A novel thioredoxinlike protein located in the chloroplast is induced by water deficit in Solanum tuberosum L. plants. Plant J. 13, 97-107. doi: 10.1046/j.1365313X.1998.00015.x

Ritz, D., Patel, H., Doan, B., Zheng, M., Aslund, F., Storz, G., et al. (2000). Thioredoxin 2 is involved in the oxidative stress response in Escherichia coli. J. Biol. Chem. 275, 2505-2512. doi: 10.1074/jbc.275.4.2505

Romero, H. M., Berlett, B. S., Jensen, P. J., Pell, E. J., and Tien, M. (2004). Investigations into the role of the plastidial peptide methionine sulfoxide reductase in response to oxidative stress in Arabidopsis. Plant Physiol. 136, 3784-3794. doi: 10.1104/pp.104.046656

Rouhier, N., Gelhaye, E., Gualberto, J. M., Jordy, M. N., de Fay, E., Hirasawa, M., etal. (2004). Poplar peroxiredoxin Q. A thioredoxinlinked antioxidant functional in pathogen defense. Plant Physiol. 134, 1027-1038. doi: 10.1104/pp.103. 035865
Sanz-Barrio, R., Corral-Martinez, P., Ancin, M., Segui-Simarro, J. M. and Farran, I. (2013). Overexpression of plastidial thioredoxin $\mathrm{f}$ leads to enhanced starch accumulation in tobacco leaves. Plant Biotechnol. J. 11 , 618-627. doi: 10.1111/pbi.12052

Sanz-Barrio, R., Fernández-San Millán, A., Carballeda, J., Corral-Martínez, P., Seguí-Simarro, J. M., and Farran, I. (2012). Chaperone-like properties of tobacco plastid thioredoxins $\mathrm{f}$ and m. J. Exp. Bot. 63, 365-379. doi: 10.1093/jxb/err282

Sanz-Barrio, R., Millán, A. F., CorralMartínez, P., Seguí-Simarro, J. M. and Farran, I. (2011). Tobacco plastidial thioredoxins as modulators of recombinant protein production in transgenic chloroplasts. Plant Biotechnol. J. 9, 639-650. doi: 10.1111/j.1467-7652.2011.00608.x

Sweat, T. A., and Wolpert, T. (2007). Thioredoxin h5 is required for victorin sensitivity mediated by a CC-NBS-LRR gene in Arabidopsis. Plant Cell 19, 673-687. doi: 10.1105/tpc.106.047563

Takahashi, S., and Murata, N (2008). How do environmental stresses accelerate photoinhibition? Trends Plant Sci. 13, 178-182. doi: 10.1016/j.tplants.2008.01.005

Tarrago, L., Laugier, E., Zaffagnini, M., Marchand, C., Le Maréchal, P., Lemaire, S. D., et al. (2010). Plant thioredoxin CDSP32 regenerates 1-Cys methionine sulfoxide reductase $\mathrm{B}$ activity through the direct reduction of sulfenic acid. $J$. Biol. Chem. 285, 14964-14972. doi: 10.1074/jbc.M110.108373

Thormählen, I., Ruber, J., von Roepenack-Lahaye, E., Ehrlich, S. M., Massot, V., Hümmer, C., et al. (2013). Inactivation of thioredoxin f1 leads to decreased light activation of ADP-glucose pyrophosphorylase and altered diurnal starch turnover in leaves of Arabidopsis plants. Plant Cell Environ. 36, 16-29. doi: 10.1111/j.1365-3040.2012.02549.x

Verdoucq, L., Vignols, F., Jacquot, J. P., Chartier, Y., and Meyer, Y. (1999). In vivo characterization of a thioredoxin $\mathrm{h}$ target protein defines a new peroxiredoxin family. J. Biol. Chem. 274, 19714-19722. doi: 10.1074/jbc.274.28.19714

Vieira Dos Santos, C., Cuiné, S., Rouhier, N., and Rey, P. (2005). The Arabidopsis plastidic methionine sulfoxide reductases B proteins: sequence and activity characteristics, comparison of the expression with plastidic methionine sulfoxide reductase $\mathrm{A}$ and induction by photooxidative stress. Plant Physiol. 138, 909922. doi: 10.1104/pp.105.062430

Vieira Dos Santos, C., Laugier, E., Tarrago, L., Massot, V., IssakidisBourguet, E., Rouhier, N., et al. (2007). Specificity of thioredoxins and glutaredoxins as electron donors to two distinct classes of Arabidopsis plastidial methionine sulfoxide reductases $B$. FEBS Lett. 581, 4371-4376. doi: 10.1016/j.febslet.2007.07.081

Vieira Dos Santos, C., and Rey, P. (2006). Plant thioredoxins are key actors in oxidative stress response. Trends Plant Sci. 11, 329-334. doi: 10.1016/j.tplants.2006.05.005

Wolosiuk, R. A., and Buchanan, B. B. (1977). Thioredoxin and glutathione regulate photosynthesis in chloroplasts. Nature 266, 565-567. doi: 10.1038/266565a0

Wolosiuk, R. A., Crawford, N. A., Yee, B. C., and Buchanan, B. B. (1979). Isolation of three thioredoxins from spinach leaves. J. Biol. Chem. 254, 1627-1632.

Zagorchev, L., Seal, C. E., Kranner, I., and Odjakova, M. (2013).
A central role for thiols in plant tolerance to abiotic stress. Int. J. Mol. Sci.14, 7405-7432. doi: 10.3390/ijms14047405

Zhang, C. J., Zhao, B. C., Ge, W. N., Zhang, Y. F., Song, Y., Sun, D. Y., et al. (2011). An apoplastic h-type thioredoxin is involved in the stress response through regulation of the apoplastic reactive oxygen species in rice. Plant Physiol. 157, 1884-1899. doi: 10.1104/pp.111.182808

Conflict of Interest Statement: The authors declare that the research was conducted in the absence of any commercial or financial relationships that could be construed as a potential conflict of interest.

Received: 11 July 2013; accepted: 12 September 2013; published online: 16 October 2013.

Citation: Rey P, Sanz-Barrio R, Innocenti G, Ksas B, Courteille A, Rumeau D, Issakidis-Bourguet E and Farran I (2013) Overexpression of plastidial thioredoxins $f$ and $m$ differentially alters photosynthetic activity and response to oxidative stress in tobacco plants. Front. Plant Sci. 4:390. doi: 10.3389/fpls.2013.00390

This article was submitted to Plant Physiology, a section of the journal Frontiers in Plant Science.

Copyright (c) 2013 Rey, Sanz-Barrio, Innocenti, Ksas, Courteille, Rumeau, Issakidis-Bourguet and Farran. This is an open-access article distributed under the terms of the Creative Commons Attribution License (CC BY). The use, distribution or reproduction in other forums is permitted, provided the original author(s) or licensor are credited and that the original publication in this journal is cited, in accordance with accepted academic practice. No use, distribution or reproduction is permitted which does not comply with these terms. 